\title{
Financial fragility and distress propagation in a network of regions
}

\author{
Stefania Vitali ${ }^{\text {a }}$, Stefano Battiston ${ }^{\mathrm{a}, *}$, Mauro Gallegati ${ }^{\mathrm{b}}$ \\ a Università Politecnica delle Marche, Department of Economics, Piazz.le Martelli 8, 60121 Ancona, Italy \\ ${ }^{\mathrm{b}}$ University of Zurich, Department of Banking and Finance, Plattenstrasse 14, 8032 Zurich, Switzerland
}

\section{A R T I C L E I N F O}

\section{Article history:}

Received 23 July 2013

Received in revised form

14 July 2015

Accepted 8 October 2015

Available online 31 October 2015

\section{JEL classification:}

F4

E32

G01

L14

\section{Keywords:}

Financial networks

Financial fragility

Financial contagion

Business fluctuations

Financial acceleration

\begin{abstract}
A B S T R A C T
We investigate how the financial fragility in the real economy is affected by the average level of interdependence among agents across different regions of the economy. To this end, we develop a parsimonious agent-based model of firms and banks organized in geographic regions. The model is built on the framework of an existing class of models for business fluctuations. The goal of our exercise is to clarify the effect on systemic failures of the interplay between network interconnectedness and financial acceleration. In particular, we investigate the probability of individual and systemic failures with varying levels of interconnectedness. We find that, in the absence of financial acceleration, connectivity makes the system more resilient. In contrast, in the presence of financial acceleration, the probability of both individual and systemic failures are minimized at intermediate level of diversification.
\end{abstract}

(c) 2015 Published by Elsevier B.V.

\section{Introduction}

In the current discussion on financial crises, two dimensions are attracting growing interest. The first is the role of geographic space, given that most financial crises of the few last decades have originated in one country and propagated to several others (Dornbusch et al., 2000; Vitali and Battiston, 2011a). The second is the role of network spillover in the propagation of financial distress, both at the level of financial institutions within a single country and at the level of countries (Allen and Gale, 2000; Kali and Reyes, 2009; Horst, 2007; Prasad et al., 2003; Stiglitz, 2010).

In this paper, we aim to address a specific question, namely how the financial fragility in the real economy is affected by the average level of interdependence among agents across different regions of the economy both along the trade and the credit dimensions. A similar question has been investigated in the case of interbank networks by means of stylized models Gai et al. (2011) and Battiston et al. (2012b) in which the interconnectivity level among the agents is fixed exogenously and the effects of different levels of interconnectivity are compared statically. In the same spirit, here we develop a parsimonious agent-based model of firms and banks organized in geographic regions by building on the framework of an existing class of models for business fluctuations (Battiston et al., 2007; Delli Gatti et al., 2005, 2007, 2009, 2010).

\footnotetext{
* Corresponding author.

E-mail address: stefano.battiston@uzh.ch (S. Battiston).
} 
Thus the goal of our exercise is to clarify the effect on systemic failures of the interplay between network interconnectedness and financial acceleration in a model firm-bank network. In particular, we investigate the frequency of individual and systemic failures with varying levels of interconnectedness. In the absence of financial acceleration, we find that higher connectivity on both trade and credit networks makes univocally the system more resilient. In contrast, in the presence of financial acceleration, more credit links lead at some point to larger and more frequent crises. Hence, the frequency of both individual and systemic failures are minimized at an intermediate level of interconnectedness.

The existence of a trade-off between diversification and contagion as interconnectedness increases has been already documented in models of interbank networks, e.g. in Wagner (2011) and in models of country networks Stiglitz (2010). However, the debate is still open and every model utilizes some more or less explicit mechanism in order to obtain the tradeoff. Our contribution here is to investigate the firm-bank case and to provide an alternative explanation for the tradeoff that relies only on the financial acceleration mechanism and not, for instance, on some ex-ante cost associated to having more links. Moreover, we show that the tradeoff emerges directly at the level of the probability of systemic defaults before even considering the social costs of crises.

More in detail, we propose a multi-agent model in which firms and banks, belonging to various regions, interact in a network of credit. As in Battiston et al. (2012b), we investigate the fragility of the system taking into consideration two main mechanisms: (i) the financial accelerator and (ii) the contagion. The financial accelerator is a positive feedback on the financial fragility of the firms. This mechanism has been discussed by the literature on financial factors as responsible for business fluctuations and transmission of shocks (Greenwald and Stiglitz, 1993; Bernanke and Gertler, 1995; Bernanke et al., 2000; Stiglitz and Greenwald, 2003). Suppose, for example, that a firm experiences negative profits. If its equity base reduces more than its liabilities, then its financial fragility, measured as debt-to-equity ratio, increases. The bank lending credit to this firm will charge a higher interest rate in order to compensate for the increased risk associated to the firm financial position. ${ }^{1}$ Higher financial costs will likely affect negatively the profits, pushing the firm into an even worse situation. In other terms, when a firm is hit by a negative shock, the probability that it will be more fragile in future periods is higher than the probability that it will be healthier. On the other hand, the contagion mechanism is due to the credit relationships between firms and banks. The financial distress of a firm affects other firms indirectly. When a firm faces consecutive losses, the bank will apply higher financing costs to all the firms in its credit portfolio. This, even if the other firms are still financially robust. Unlike in Battiston et al. (2012b), here we develop a richer model where balance sheets of agents evolve in time and become endogenously heterogeneous.

We do not aim to model here the evolution of the links among agents. Moreover, in our model the allocation of credit to firms and the demand of credit from firms to banks is only stylized. We do not model these aspects through optimization decision rules. Instead, we are interested in the point of view of the regulator who seeks to know what would be the desirable level of the average connectivity. To this end, we compare the default probability at different levels of connectivity that is homogeneous across agents and fixed exogenously as done in previous works, e.g. Gai et al. (2011), and Battiston et al. (2012b).

The main result of the model is that as long as regions are economically separated, agents do not benefit from potential access to other markets and they may be only affected by local financial instability. In contrast, when firm and banks can establish inter-regional relationships, although they benefit from diversification of individual risk, they are also exposed to financial contagion. In our model, risk diversification and interdependence, arising from economic integration among regions, go hand in hand.

The intuition suggests that as long as regions are economically separated, agents are not able to benefit from the potential access to other markets, but in exchange they are only affected by local financial instability and protected from global crises. In the case where agents have access to cross-region counterparties, both firms and banks benefit from individual risk diversification, but they are also exposed to systemic risk, i.e. the collapse of a large portion of the economic system. It is often argued that the more systemic (e.g. larger and severe) the distress event is, the more rare it is (e.g. less frequent). Our model shows instead that, in the presence of financial acceleration, when the economy is interconnected above a certain threshold, systemic events are not only larger but they are also more frequent.

Given the purpose of our exercise, we have made a number of simplifications and assumptions. For instance, we focus only on the bank-firm interaction, while we neglect the interaction among firms and the one among banks. We also neglect the effect of up- and down-turns of the economy on demand and prices. Moreover, although, over time, agents become endogenously heterogeneous in size, we make a strong assumption of symmetry regarding the number of their links and the geometry of their interactions. These hypotheses could be relaxed, certainly making the model more realistic, but would not help very much in addressing the question we address here. ${ }^{2}$ Notice also that by assuming that the transmission of instability between firms happens only indirectly via the banks, makes the scenario of the model setting more conservative. In contrast, introducing also direct firm-firm relations as in Battiston et al. (2007) and Delli Gatti et al. (2009) would amplify the contagion and the emergence of larger avalanches of bankruptcies. Analogously, introducing correlations and feedback loops between up(down)-turns and prices or level of demand would exacerbate the instability of the economy.

\footnotetext{
${ }^{1}$ When the spread of a crisis across markets threatens the financial stability of countries, central banks usually adopt counteracting measures, such as reducing the interest rate in the attempt of making easier for firms and households to obtain the extension of loans from banks. For the sake of simplicity, in our model we do not consider any intervention by central banks.

${ }^{2}$ For completeness, some robustness analyses with empirical and heterogenous network structures are reported in the Appendix.
} 
The paper is organized as follows. Section 2 provides references to the relevant literature and Section 3 gives a general overview of the assumptions of the model and the timing of the events. Then, Section 4 describes the dynamics of the baseline model (Section 4.1), provides a network interpretation of the economic system (Section 4.2) and compares our baseline model with the model of Delli Gatti et al. (2005, 2009) (Section 4.3). Section 5 expands the framework of the baseline model. Section 6 discusses the model and deals with the results of the computer simulations. Finally, Section 7 concludes. In Appendix A we describe the simulation procedure and in Appendix B we report some robustness checks.

\section{Related work}

A growing number of works investigate the spread of distress across networks of institutions and countries - see e.g., Allen et al. (2012), Stiglitz (2010), Kali and Reyes (2009), and Horst (2007).

A common approach consists in comparing the resilience of different network architectures - see e.g., Allen and Gale (2000) and Allen et al. (2012). In particular, our paper shares the approach of several works (Gai and Kapadia, 2010; Gai et al., 2011; Battiston et al., 2012b,a) to focus on different levels of average connectivity given as exogenous. Moreover, in line with a body of existing works, our paper looks at how aggregate patterns of failures emerge from individual interactions among firms and/or banks (Delli Gatti et al., 2005, 2009; Iori et al., 2006; Battiston et al., 2007).

In the last decade, the network approach has been extensively applied in many fields, included economics and finance (Vitali et al., 2011; Martínez-Jaramillo et al., 2010; Haldane, 2009; Lublóy and Szenes, 2008; Stark and Vedres, 2006; Jackson and Watts, 2002). For instance, it has been used in the investigation of innovation networks (König et al., 2011, 2012), financial contagion and inter-bank relationships (Allen and Gale, 2000; Iori et al., 2006; Nier et al., 2007; Cajueiro and Tabak, 2008; Lorenz and Battiston, 2008; Amini et al., 2012). In the same vein, it has been applied to the analysis of trade credit among suppliers of intermediate goods (Battiston et al., 2007). In Delli Gatti et al. (2009), instead, both trade and credit networks are modeled. In this case, there are two levels of firms, interacting via the supply of intermediate goods and credit. Firms in the lower level of the chain sell the final output in the good market and borrow from a single bank. In line with this approach, we build on the model of Delli Gatti et al. (2005).

Since the pioneering work of Allen and Gale (2000), a number of works have considered the geographical aspect of financial contagion (Dasgupta, 2004; Goldstein and Pauzner, 2004). In this paper, we also introduce a geographic component. By allowing firms to cross regional borders and obtain credit from foreign banks, regions get connected in a network of financial linkages. These linkages emerge from the relation between firms and banks.

Empirical studies of firm-bank relations have been carried out for several countries, such as Italy (De Masi and Gallegati, 2007; Detragiache et al., 2000), Germany (Agarwal and Ann Elston, 2001), Japan (Ogawa et al., 2007), Portugal (Farinha and Santos, 2002) and Belgium (Degryse and Ongena, 2005). These investigations show that firms, regardless their size, tend to borrow from several banks. E.g., in Italy and Portugal, each firm on average borrows from more than 10 banks. A larger number of relations increases transaction costs (e.g., for firms, the renegotiation of loans) and monitoring costs (e.g., for banks, the surveillance of borrower's wealth). However, there are also substantial benefits, including (i) access to additional lines of credit for firms and (ii) diversification of credit risk for banks.

\section{The model at a glance and timing}

We consider the economy as portioned in several regions, which are isolated (e.g., the agents of a region can interact only with other agents of the same region) in the baseline version of the model (see Section 4), while they get integrated in the second version (see Section 5). In this section, we sketch the timing and the general settings of the model, while the problem of the firm and the one of the bank are described in detail in the following sections.

In the economy, there are $n_{z}$ regions, each populated by $n_{b}$ banks, and a number $n_{f}$ of firms. For our purposes, in the present work, we set $n_{b}=1$, since we are focusing on the contagion across regions. In other contexts, the case $n_{b}>1$, possibly heterogeneous, may be more appropriate.

Each firm $i$ borrows credit establishing a credit link with a number $k_{i}$ of different banks. Overall, the total number of firms equals $n_{f} \cdot n_{z}$; the total number of banks equals $n_{b} \cdot n_{z}$; the number of credit relationships per firm is $1<=k_{i}<=n_{z}$. Note that in the case of isolated regions, all the firms borrow only from their regional bank, $k_{i}=1$. Instead, with increasing integration all firms have a number $k_{i}>1$ of credit relationships.

At each time step $t$, the firms define the optimal level of capital needed for the production, by maximizing the expected profits in the presence of bankruptcy costs. Then, given such an optimal capital level, they define the amount of credit to be borrowed from the banks. In turn, the banks offer credit to each firm proportionally to their equity level and at an interest rate which depends on (i) the trend of financial robustness of the borrowing firms and (ii) the share of financially fragile firms in their portfolio. Once the firms have received credit, they produce and sell the goods in the market. For each firm, the selling price of the output is exogenously given and varies stochastically around an average market price. The firms' profits are positive, if the revenue is higher than the financial and production costs, and negative otherwise. Profits accrue to equity of period $t$ and determine the production in the future period $t+1$. If firms face negative equity, because of large and/or consecutive losses, they exit the market. At $t+1$ they are replaced by new firms. In the same way, also the banks can perform 
positive or negative profits, depending on the solvency of their borrowing firms (for a diagram of the workflow of the model, see Fig. A1).

\section{Baseline model of isolated regions}

We first consider the case in which all the regions are isolated. The system can be conceived as an archipelago of islands, where the economic actors in each region have neither commercial nor financial relationships with the economic actors of other regions.

\subsection{Dynamics}

\subsubsection{The firms}

The financial situation of each firm is described by the stock variables in its balance sheet. The three parts of the balance sheet, assets (non-mobile capital asset) $K$, liabilities $L$ and equity $E$ satisfy the accounting equation:

$$
K_{i, t}=L_{i, t}+E_{i, t} \text {. }
$$

On the basis of this identity, we take as measure of firm financial fragility the ratio $\phi_{i, t}=L_{i, t} / E_{i, t}$ (Delli Gatti et al., 2009). We will refer to it as the debt-equity ratio, or leverage ratio in the following. In every period $t$, each firm produces a homogeneous good which is sold in the domestic region. The production function uses only capital $K_{i, t}$ as input:

$$
Y_{i, t}=\gamma K_{i, t},
$$

where $0<\gamma<1$ is the capital productivity. Capital does not depreciate and is subordinated to a minimum efficient scale requirement, $K_{i, t}>K^{\mathrm{min}}$. The demand of goods is completely inelastic and the whole production is sold in the market. In other words, firms sell all the output they optimally decide to produce. Therefore, we exclude the accumulation of inventories.

The relative price of the firm output is exogenous. As in Greenwald and Stiglitz (1993), in the good market the company is "price taker". It does not define the price of the goods $P_{i, t}$, which, instead, is a stochastic variable:

$$
P_{i, t}=u_{i, t} .
$$

We assume $u_{i, t}$ being a random variable uniformly distributed on the support [0,2], with $E\left(u_{i, t}\right)=1$ and variance $V\left(u_{i, t}\right)=1 / 3$. One can think of such prices as an increasing function of the demand variability if the demand is sufficiently elastic. Consequently, a high value of $u_{i, t}$ can be interpreted as a situation of high demand that rises the relative price of the goods, while a low $u_{i, t}$ refers to a low demand and may lead the firm to exit the market if it cannot cover the costs. As a result, the profits of each company are given by the difference between the revenue and the costs:

$$
\begin{aligned}
& \pi_{i, t}=u_{i, t} Y_{i, t}-\psi Y_{i, t}-r_{i, t} L_{i, t}-r_{i, t} E_{i, t-1} \\
& \pi_{i, t}=u_{i, t} Y_{i, t}-\psi Y_{i, t}-r_{i, t} K_{i, t},
\end{aligned}
$$

where $\psi Y_{i, t}$ are the production costs, proportional to the output, with $0<\psi<1$, and $r_{i, t}$ is the interest rate. For the sake of simplicity, we have assumed that the rate of remuneration of the equity base $E_{i, t}{ }^{3}$ coincides with the interest rate $r_{i, t}$. Notice that, moreover, we assume that firms do not pay dividends.

The net worth of the company is defined as the original stock plus the profits of the business activity, and it evolves according to the law of motion:

$$
E_{i, t}=E_{i, t-1}+\pi_{i, t} .
$$

Negative profits erode the net worth of the firm. Without loss of generality, we assume bankruptcy to occur whenever $E_{i, t}<0$. Thus, the probability of bankruptcy $\mathcal{P}^{b}$ for firm $i$ can be written as follows:

$$
\begin{aligned}
& \mathcal{P}_{i}^{b}=\mathcal{P}\left\{E_{i, t}<0\right\} \\
& \mathcal{P}_{i}^{b}=\mathcal{P}\left\{E_{i, t-1}+\pi_{i, t}<0\right\} \\
& \mathcal{P}_{i}^{b}=\mathcal{P}\left\{E_{i, t-1}+u_{i, t} Y_{i, t}-r_{i, t} K_{i, t}-\psi Y_{i, t}<0\right\} \\
& \mathcal{P}_{i}^{b}=\mathcal{P}\left\{u_{i, t}<u_{i, t}^{*}=r_{i, t} K_{i, t} Y_{i, t}+\psi-E_{i, t-1} Y_{i, t}\right\},
\end{aligned}
$$

where $u_{i, t}^{*}$ defines the critical value of the selling price. If firm $i$ faces a price below $u_{i, t}^{*}$, it goes bankrupt. Since we assumed prices to follow a uniform distribution $p(u)$ in [0,2], it holds $\mathcal{P}_{i}^{b}=\int_{0}^{u_{i, t}^{*}} p(u) d u=\frac{1}{2} u_{i, t}^{*}$. For instance, $\mathcal{P}_{i}^{b}=0.5$ if $u_{i}^{*}=1$. Moreover, $\mathcal{P}_{i}^{b}$ increases when, ceteris paribus, (i) the net worth at $t-1$ decreases, (ii) the capital and the total debt increase, and

\footnotetext{
${ }^{3} E_{i, t}$ is the level of equity of the end of the period $t-1$ and of the beginning of $t$.
} 
(iii) the variable costs increase. Given that the equity base of the previous period depends on the past profits, the history of the firm profits affects the current probability of bankruptcy, i.e., there is path dependence.

We assume a simple entry-exit dynamics: each failed firm is replaced by a new entrant firm, according to a one-to-one replacement rule. Therefore, the total number of firms in the economy remains constant across time.

Each firm sets its desired level of production by maximizing the expected level of profits (i.e., $E\left(\pi_{i, t}\right)$ ) minus the expected bankruptcy costs (i.e., $E\left(C_{i, t}^{b}\right)$ ). Following Greenwald and Stiglitz (1993), we assume that the bankruptcy costs are monotonically increasing and convex with the level of production:

$$
C_{i, t}^{b}=c Y_{i, t}^{2} \text {, }
$$

where $c$ is a constant. ${ }^{4}$ Thus, the problem of the firm can be expressed in the following terms:

$$
\begin{aligned}
\max _{K_{i, t}} & {\left[E\left(\pi_{i, t}\right)-\mathcal{P}_{i}\left\{u_{i, t}<u_{i, t}^{*}\right\} C_{i, t}^{b}\right] } \\
\text { s.t. } & K_{i, t}>K^{\min },
\end{aligned}
$$

the objective function to be maximized takes the form:

$$
\Gamma=\left(\gamma K_{i, t}-r_{i, t} K_{i, t}-\psi \gamma K_{i, t}\right)-\frac{c}{2}\left(\frac{r_{i, t} K_{i, t}}{\gamma K_{i, t}}+\psi-\frac{E_{i, t-1}}{\gamma K_{i, t}}\right)\left(\gamma K_{i, t}\right)^{2},
$$

and the first order condition yields:

$$
\frac{\delta \Gamma}{\delta K_{i, t}}=\left(\gamma-r_{i, t}-\psi \gamma\right)-\left(c \gamma r_{i, t} K_{i, t}-\psi c \gamma^{2} K_{i, t}+\frac{c \gamma E_{i, t-1}}{2}\right) .
$$

The optimal level of capital, $K_{i, t}^{*}$, is given by:

$$
K_{i, t}^{*}= \begin{cases}\frac{1}{\left(r_{i, t}+\psi \gamma\right)}\left(\frac{1-\psi}{c}-\frac{r_{i, t}}{c \gamma}+\frac{E_{i, t-1}}{2}\right) & \text { if } K_{i, t}^{*}>=K^{\min }, \\ K^{\min } & \text { otherwise. }\end{cases}
$$

Eq. (15) implies that firm desired level of production is a function of net worth and interest rate (as in Greenwald and Stiglitz, 1993; Delli Gatti et al., 2005, 2009) and has a minimum. In principle, firms can freely adapt the level of production, so to match their financial conditions. However, in a real economy, they often face constraints on reducing their production capacity and their accumulated capital (because of, e.g., costs of assets liquidation and capital hoarding). As a result, they may prefer to maintain the current level of production, waiting for future better conditions (Battiston et al., 2007). Thus, when the optimal capital for the production is less than the firm capital stock, the net capacity is reduced by a constant fraction $\eta \in(0,1)$. The law of motion of the capital stock is given by:

$$
K_{i, t}^{d}= \begin{cases}\eta K_{i, t-1} & \text { if } K_{i, t}^{*}<\eta K_{i, t-1}, \\ K_{i, t}^{*} & \text { otherwise. }\end{cases}
$$

Note that, without this assumption, there can exist situations in which companies may not borrow credit from banks. Indeed, after facing a large negative shock, the firm optimal capital stock required reduces considerably. Such reduction of capital may be enough to cut down the amount of liabilities to zero and, consequently, terminate the credit relationship with the bank.

Once the desired capital is determined, the investment of firm $I_{i, t}$ is given by:

$$
I_{i, t}=K_{i, t}^{d}-K_{i, t-1} \text {. }
$$

This quantity can be positive or negative, depending on whether firms reduce or increase the capital. In line with Greenwald and Stiglitz (1993), we assume that firms operate in a regime of equity rationing constraints. This means that firms prefer to finance their production by loans instead of issuing equity. Therefore, firms can pool funds from two channels: internally, with retained profits, and in the credit market, with bank loans. The demand of credit varies according to the profits from the previous period and to the current investment:

$$
L_{i, t}=L_{i, t-1}-\pi_{i, t-1}+I_{i, t} .
$$

Notice that the loans do not correspond to short-term credit, but to long-term contractual relationships. Thus, only the interest has to be paid at the end of each period $t$ (see Delli Gatti et al., 2005). The debt commitment of each firm will be $r_{i j, t} L_{i j, t}$, where $r_{i j, t}$ is the interest rate charged by bank $j$ to firm $i$. Given that in this baseline model firms borrow credit from only one bank, we simplify the notation omitting the reference to the bank.

\footnotetext{
${ }^{4}$ According to Greenwald and Stiglitz (1993), bankruptcy costs should increase with the level of firm output for at least three reasons: (i) as firms become larger, they presumably involve more managers which, in case of insolvency, have less power of intervention; (ii) managers usually choose the level of output, consequently, bankruptcy with high levels of output should reflect unfavorably on their ability to take judgment; and (iii) it ensures that the possibility of bankruptcy is never ignored, while with fixed costs it may have a negligible consideration.
} 


\subsubsection{The banks}

In our model, financial institutions are the only sources of external funds for firms and, for simplicity, we assume them to be commercial banks. Their balance sheet respects the identity: $L_{t}=E_{t}+D_{t}$, where $L$ is the total credit supply, $E$ is the bank's net worth and $D$ are the total deposits, set as a residual. We assume that each bank $j$ can lend at most a multiple of its net worth:

$$
L_{j, t}^{s}=\frac{E_{j, t-1}}{\alpha}
$$

with $0<\alpha<1$. This assumption is in line with the idea of minimal capital requirement imposed by international agreements (e.g., Basel I and II). Moreover, credit is allotted to each firm $i$ according to its relative size, that is, to the ratio of the firm current equity base over the total net worth of all the borrowing firms $G$ :

$$
L_{j i, t}^{s}=L_{j, t}^{s} \frac{E_{i, t}}{\sum_{i=1}^{G} E_{i, t}} .
$$

Firms borrow only the amount needed for their desired output, even when the credit supplied by the bank could exceed the demand for funding. When supplied credit is smaller than the requested amount, firms adjust the production to the level of funding they have obtained.

The interest rate that bank $j$ charges to firm $i$ is assumed to result from the combination of three terms:

$$
r_{i, t}=\bar{r}+r_{i, t}^{f}\left(\phi_{i, t}\right)+r^{b}\left(P_{j, t}\right)
$$

The first term $\bar{r}>0$ is a base rate, which is the same across firms and can be thought of as the risk-free rate. The second term, denoted as $r_{i, t}^{f}\left(\phi_{i, t}\right)$, accounts for the riskiness of the borrowing firm and is responsible for the mechanism of financial acceleration (Bernanke et al., 2000; Battiston et al., 2012b). The rationale is that the bank increases the rate to the firm, when its fragility experiences a positive variation that is larger than that expected on the basis of the amplitude of price fluctuations. Conversely, the bank decreases the rate to the firm in the opposite case. Thus, this term varies over time depending on the shocks hitting the fragility, according to the following dynamics.

$$
r_{i, t}^{f}\left(\phi_{i, t}\right)= \begin{cases}\min \left\{r_{i, t}^{f}\left(\phi_{i, t-1}\right)+a, r_{\text {max }}^{f}\right\} & \text { if } \Delta \phi_{i, t}>=\theta \sigma \\ \max \left\{r_{i, t}^{f}\left(\phi_{i, t}\right)-a, 0\right\} & \text { if } \Delta \phi_{i, t}<\theta \sigma_{z},\end{cases}
$$

where $a, \theta>0$ are parameters and $\sigma$ is the standard deviation of prices $\sigma=\sigma_{u}$.

Three remarks are important here:

- The equation above implies that this component of the rate is non-negative and cannot exceed the maximum value $r_{m a x}^{f}$.

- The parameter $a$ can be interpreted as the amplitude of the reaction of the bank to a change in firm financial fragility. It is a fixed percentage that the bank increases (decreases) to the firm previous level of interest rate, when this is affected by a shock larger (in absolute value) than $\theta$ times the standard deviation of the stochastic price. Thus, the parameter $\theta$ can be thought of as the sensitivity of the bank to the change in firm financial fragility. Notice that the law of motion of this term of the interest rate is similar to the law of motion of the firm robustness in Battiston et al. (2012b). There, the robustness of the firm decreases by a fixed amount every time the firm is hit by an unusual negative shock. Here, in contrast, it is the interest rate that increases or decreases by a fixed amount when the firm is hit by an unusual negative or positive shock. Overall, the mechanism is essentially the same and leads to the so-called trend reinforcement. If the firm is first hit by an unusual negative shock, the fact that the bank raises the interest rate increases the chances that the firm makes a negative profit in the next period and thus to experience another unusual variation in fragility. Conversely, in the case of a positive shock. ${ }^{5}$ Notice that "unusual" refers here to the variation that would be expected based on the price fluctuations in the market.

- Over time $r_{i, t}^{f}$ is a function of $\phi_{i, t}$ resulting from its stochastic dynamics. Although it is not possible to write this function in closed form, the resulting relation between $r_{i, t}$ and $\phi_{i, t}$ is illustrated in Figs. B1 and B2 of Appendix B.1. The interest rate increases monotonically with increasing fragility and saturates around a maximum value (Greenwald and Stiglitz, 1990).

The third term accounts for the credit risk of the lender, i.e. it depends only on the bank $j$ itself (see, for instance, the optimal debt contract in Bernanke and Gertler, 1989). The bank sets this component of the interest rate for every firm $i$ in its portfolio as a function of the fraction of the borrowers in its portfolio that are hit by unusual shocks. This means that even firms that are not hit by unusual shocks see their interest rate increased. The same mechanism has been used in several previous modeling works, the rationale being the asymmetric information regarding the actual financial soundness of the firms (Delli Gatti et al., 2010; Boissay, 2006).

In our model, the bank can observe the level of financial fragility as measured by the ratio $\phi_{i}$ of debt over equity of each firm. However, when several firms are hit by unusual shocks the bank fears that the other firms will also experience similar

\footnotetext{
${ }^{5}$ In Battiston et al. (2012b) trend reinforcement works only for negative shocks while here it is more general and works symmetrically. Lorenz and Battiston (2008) also use a symmetric trend reinforcement mechanism which they map formally into the so-called "persistent random walk".
} 
negative shocks. Clearly, this mechanism generates a negative externality from the firms hit by unusual shocks to the others. Notice that this is the only channel of financial contagion across firms that we assume in our model.

In formal terms:

$$
r^{b}\left(P_{j, t}\right)=r_{\max }^{b} \frac{\left|P_{j, t}^{d}\right|}{\left|P_{j, t}\right|}, \quad P_{j, t}^{d}:=\left\{z \in P_{j, t} \mid \Delta \phi_{z, t}>\theta \sigma\right\} .
$$

In the expression above, $r_{\max }^{b}$ is the maximum rate charged by the bank according to the level of distress in its portfolio, $P_{j, t}$ denotes bank $j$ 's credit portfolio to firms, while $\left|P_{j, t}\right|$ denotes its cardinality, i.e. the number of firms which bank $j$ lends to. $P_{j, t}^{d}$ is a subset of firms, belonging to bank $j$ 's portfolio, that are hit by unusual shocks at time $t$.

The banks' profit is the difference between their revenues and the remuneration of the deposits and investors:

$$
\pi_{j, t}=\sum_{i} r_{i, t} L_{i, t}-r_{j, t}^{D} D_{j, t-1}-r_{j, t}^{E} E_{j, t-1}
$$

For the sake of simplicity, we assume that the rate of interest on deposits and the rate of return of the bank's equity are equal to zero: $r_{j, t}^{D}=r_{j, t}^{E}=0$, then Eq. (24) yields:

$$
\pi_{j, t}=\sum_{i} r_{i, t} L_{i, t}
$$

The equity base of the banks obeys the following law of motion:

$$
E_{j, t}=E_{j, t-1}+\pi_{j, t}-B_{j, t},
$$

where $B_{j, t}$ is the sum of the bank losses due to the failure of its borrowing firms. Recalling that a firm goes bankrupt when $E_{i, t}<0$, that is, when it is not able to pay back its liabilities, $K_{i, t}-L_{i, t}=E_{i, t}$ (cfr. Eqs. (6) and (7)), the bank's bad debt is:

$$
B_{j, t}=\sum_{i: E_{i, t}<0}-E_{i, t}
$$

Finally, as firms, banks go bankrupt when their equity level become negative and are replaced by new entrant banks in the following period. In this way, firms can immediately have access to credit from the new bank. ${ }^{6}$

\subsection{Network description}

The economy can be represented as a graph of nodes (i.e., firms and banks) and directed links (i.e., loan relations). Liabilities, thus, form a matrix $L$ in which firms are listed along the rows and banks along the columns. The element $L_{i j}$ of the matrix is non zero, if and only if firm $i$ borrows from bank $j$. The value of the element indicates the nominal value of the debt of firm $i$ towards bank $j$, and, at the same time, the amount claimed by bank $j$ to firm $i$.

In this baseline model, the regions are separated and each region has only one bank. Thus, the corresponding network consists of several disconnected stars. ${ }^{7}$

\subsection{Comparison with previous models}

In our baseline model, the economic dynamics of each region in isolation is very similar to the one introduced in the Delli Gatti et al. (2005), with the following main differences. First, in Delli Gatti et al. (2005) the interest rate charged by the banks is given by the equilibrium between credit demand and credit supply. In contrast, we model the interest rate close to the model of Delli Gatti et al. (2009), where the rate depends on the firm leverage ratio and on the bank's bad debt. Second, we define the optimal level of production following the method suggested in Delli Gatti et al. (2005), i.e., considering both the expected profits and the expected bankruptcy costs. We have also introduced: (i) a constraint in the reduction of the level of capital and (ii) a minimum requirement of capital for the production. Thirdly, while they have assumed that the population in the system grows in time, in our model it remains constant. Finally and most importantly, we have included the geographical component. Even though in this baseline version of the model it does not play any role, it becomes important when the regions open their borders and the agents establish connections with agents of other regions (see Section 5). Indeed, as we will see, the economic and financial integration affects the individual and the systemic probability of failure. ${ }^{8}$

\footnotetext{
${ }^{6}$ The new bank is born with a fixed endowment of net worth. Therefore, after the failure of a bank, the only effect is a possible decrease in the supply of credit to firms.

7 Since there are no links among banks nor among firms, the network is a bipartite graph.

${ }^{8}$ However, the above differences do not change substantially the emerging stylized facts of the economy w.r.t. to the model of Delli Gatti et al. (2005). We have verified that there is a qualitative agreement with the results of that model. More information is available upon request.
} 


\section{Model of integrated regions}

We now extend the baseline model by allowing for a flow of goods and credit among regions. The objective is to investigate how the level of integration affects the probability of both individual and systemic failures. To do so, we study the dynamics of the whole economy for fixed levels of average openness of the regional borders. The incentive for firms to cross regional borders and sell their goods in other regions is to take advantage of price diversification. Since prices are stochastic and independent in each region, firms can reduce the price fluctuation by selling shares of output in several markets. At the same time, they have access to the credit markets of these other regions by borrowing from the banks located there. This is in line with the empirical evidence that trade and financial openness tend to go hand in hand both for industrialized and emerging markets (IMF, 2006).

\subsection{The network}

In order to avoid confusion in the following, let us emphasize that the only type of relation among agents that is assumed and modeled in this paper is the relation of credit between a firm and a bank (the firm borrows and the bank extends the credit). When firms borrow only from the bank of their own region, they are indirectly connected, via the bank, to all - but only - the other firms in that region. When firms borrow from banks of several other regions, firms are indirectly connected via the banks also to the firms of these other regions.

In principle, the connections among firms and banks could be arranged in very many possible network structures. For instance, one could model the endogenous formation of linkages among banks and firms (Delli Gatti et al., 2010), or one could assume a network structure that reflects the empirical distribution of the number of banks per firm (De Masi and Gallegati, 2007) (see the robustness analysis carried out in Appendix B.2).

In this paper, similar to the approach of several previous works - e.g. Gai et al. (2011), Battiston et al. (2012a,b) - we want to study the effect of the network density on financial stability in an homogeneous network. In other words, we address the specific question of how the average level of connectivity affects the failure probability. To this end, we assume a symmetric structure, where each firm is borrowing from the same number $k$ of banks. ${ }^{9}$

Even under this strong assumption, there are still several ways of arranging the links. For the sake of simplicity, we assume the following arrangement, which is often used in the literature on economic networks and geography (see e.g. Carayol et al., 2008). Regions are positioned in a ring and, for a given level of connectivity $k>1$, firms borrow from the $k-1$ closest banks in clockwise direction. For instance, firms in region 1 are indirectly connected to firms in region 2 via the bank of region 2, and there is a path of length 2 among these firms. Firms in region 1 are connected even to firms in region $n_{z}$, via a path of $2\left(n_{z}-1\right)$ indirect links. In this way, already with $k=2$ we ensure that there are no isolated regions. For higher levels of $k$, the distance among firms in different regions decreases. When $k=n_{z}-1$, for any two chosen regions $z_{1}$ and $z_{2}$, all firms of $z_{1}$ are connected to firms of $z_{2}$, through the bank of $z_{2}$, and thus with a path of length 2 . This arrangement is referred to as "clockwise" in the following.

Notice that the above construction corresponds to a conservative assumption on the spreading of crises from a region to another because financial contagion can only propagate in one direction. The reverberation of contagion (from the "infected" agent back to the "infector") is ruled out by construction, thus reducing the potential amplification of distress. The connectivity $k$ and the network structure are exogenous and fixed during the dynamics. One could introduce a mechanism allowing firms to switch from a bank to another one (e.g., because it offers a lower interest rate). However, this would lead to an evolving topology and would not allow us to focus on the question of how aggregate patters of the dynamics are affected by varying levels of $k$.

We check the robustness of the results with a "side-to-side" arrangement, in which at every density level a link is added both the region to the left and to the right. Finally, in the Appendix, we consider the case in which starting from empirical data of the Japanese firm-bank relationships, we gradually increase the connectivity $k$ by adding random links.

\subsection{Dynamics}

\subsubsection{The firms}

With the openness of trade relationships to other regions, firms have the opportunity to reduce the variability of their revenues. Although the optimal capital (determined via Eq. (15)) is, for given financial conditions, the same as in the case of isolated regions, the average selling price is now closer to its expected value. To make this point clear, suppose that firm $i$ sells the output in several regions, $k_{i}>1$. The total revenue is given by the sum of the quantity sold in each region $z, y_{i, z, t}$, times the selling price faced in that region. For the sake of simplicity, we assume that the shares $s_{i}$ of goods sold by firm $i$ in each region $z$ are the same across regions, $s_{i, t}=1 / k_{i}$. Thus, the firm total revenue is:

$$
R_{i, t}=\sum_{z=1}^{k_{i, t}} u_{i, z, t} y_{i, z, t}=\sum_{z=1}^{k_{i, t}} u_{i, z, t} \frac{y_{i, z, t}}{Y_{i, t}} Y_{i, t}=\sum_{z=1}^{k_{i, t}} u_{i, z, t} s_{i, t} Y_{i, t}=\frac{1}{k_{i}}\left(\sum_{z=1}^{k_{i, t}} u_{i, z, t}\right) Y_{i, t} .
$$

\footnotetext{
${ }^{9}$ Random graphs can be expected to behave closely to symmetric graphs in our model.
} 
It then follows that total revenue is proportional to the average of the prices faced by $i$ across regions. Since in each region firms face prices which are independent stochastic variable with the same standard deviation $\sigma_{u}$, the standard deviation of the average price $\bar{u}$ for firm $i$ is smaller than and equal to $\sigma=\sigma_{u} / \sqrt{k_{i}}$. Thus, by selling their output in many regions, firms diversify the risk associated to price shocks. This is similar to the diversification of asset returns assumed in Battiston et al. (2012b). Furthermore, we assume that the network is symmetric, that is, each firm sells the same amount of goods in the same number of regions, that is, $k_{i}=k$. Therefore, the amplitude of the average price faced by all firms is the same: $\sigma=\sigma_{u} / \sqrt{k}$.

Not only there is a flow of goods, but also a flow of loans among regions. Indeed, firms diversify their bank portfolio asking for credit to the financial institutions $j$, located in the new regions where they also sell goods. Consequently, the firm profits are now described by the following equation:

$$
\pi_{i, t}=\left(\frac{1}{k} \sum_{z=1}^{k_{1, t}} u_{i, z, t}\right) Y_{i, t}-\sum_{j} r_{i j, t} L_{i j, t}-\tilde{r}_{i, t} E_{i, t-1}-\psi Y_{i, t},
$$

where $r_{i j, t} L_{i j, t}$ corresponds to the financial costs to be payed by firm $i$ to all its lending banks $j=1, . . k$, and $\tilde{r}_{i, t}$ is the average interest rate charged to firm $i: \tilde{r}_{i, t}=(1 / k) \sum_{j=1}^{k} r_{i j, t}$. Because profit fluctuations are mainly driven by price fluctuations, the distribution of profits is also rescaled so that the amplitude of the typical profit fluctuation is reduced by a factor $1 / \sqrt{k}$.

\subsubsection{The banks}

In the case of a connected economy, the interest rate charged by the banks to each firm still follows Eq. (21), where it is now $\sigma=\sigma_{u} / \sqrt{k}$. In other words, the behavioral rule of banks does not change w.r.t to the case of isolated regions. What changes is the distribution of profits, as explained in the previous section about firms. Such new value of $\sigma$ indicates that banks react to the new level of profit fluctuations. However, it is clear that the probability that a firm experiences variations larger than the standard deviation $\sigma$ is constant, because both shocks and standard deviation are rescaled by the very same factor. This means that the probability that a firm is hit by a shock that induces the bank to increase the interest rate is completely independent of the connectivity level $k$. As a consequence, at all levels of diversification firms have, ex-ante, the same opportunities. That is, our model does not penalize a more diversified market. For a more formal argument on this point, see Battiston et al. (2012b).

However, notice also that the adjustment of the interest rate is carried out by discrete changes of fixed amplitude $a$. This is where too much diversification can be harmful. A highly diversified firm that fulfills condition (22) (first case) a first time is likely to fulfill it also in the next period. Indeed once a firm is subject to an increase in interest rate, it needs a positive and large enough shock in order to escape the trend and not to be subject to a further increase in the next period. Because well diversified firms have smaller fluctuations, this is less likely to happen. In other words, when firms are too much diversified they progressively lose the ability to escape the downward spiral of net worth. This mechanism is similar to the one described in Battiston et al. (2012b). Therefore, the fact that at higher levels of $k$ the trend reinforcement is more likely to be triggered is an unanticipated effect of the behavioral rule used by the bank and it arises as an externality.

In addition, at a high level of integration, the contagion mechanism (Eq. (23)) increases the correlation among the values of fragility of firms located in connected regions. Indeed, a large number of firms belonging to different regions become connected via banks, and the financial fragility suffered by one of them can be directly transmitted to the others. Consequently, with increasing integration, also the probability of simultaneous failures rises.

In contrast to the baseline model of Section 4, now firms can obtain credit from more than one bank and have to decide how much credit to accept from each of them. The banks allocate the credit considering the relative net worth of each borrowing firm, which is used as a proxy for collateral, as shown in Eq. (20). Once the firms know how much they can borrow from each bank $j$, and at which interest rate, they order the credit supplied by increasing interest rate and borrow more from the first and less from the last banks in the rank (according to the rule: $\left.L_{i, t}\left(\left(1 / r_{i j, t}\right) /\left(1 / \sum_{j} r_{i j, t}\right)\right)\right)$, as long as all their credit demands are satisfied.

Note that, although firms prefer to borrow from the banks with the lowest interest rate, at the same time, they keep open more than one line of credit. This assumption relies on two main motivations. On the one hand, empirical studies (Sharpe, 1990; Degryse and Van Cayseele, 2000; von Thadden, 2004) found that the firm-bank relations usually last for long periods, because the firm switching from one bank to another one is costly. Indeed, a bank gains information on its borrowing firm over time, generating a lock-in problem to that firm that cannot transfer costlessly to another lender what its bank knows about it. Thus, the loan interest rate a firm $i$ accept by a bank $j$ might be higher than the one offered by other new banks. On the other hand, we intended to capture a typical behavior of firms, which prefer to maintain a bank portfolio, even if this is costly, in order to reduce the risk of liquidation in bad periods, i.e. the inability to roll over existing debt (Detragiache et al., 2000; Ongena and Smith, 2000). This could be seen as a sort of profit maximization over a longer term. However, since we assume that firms operate under incomplete information and bounded rationality, they are not able to estimate exactly the probability of not obtaining funds from a given bank. Consequently, they are not able to determine an optimal portfolio size. Thus, we assume that firms are willing to reduce the risk of running out of credit by keeping open more than one line of credit, depending on the credit supply.

The law of motion of the bank's equity level does not change, while the bad debt is now calculated considering the credit diversification of the firm. The entity of the loss caused to the bank by the firm bankruptcy is shared among all the banks the 
firm is linked to, proportionally to the amount lent. Formally, the bad debt of the bank $j$ is:

$$
B_{j, t}= \begin{cases}\sum_{i} L_{i j, t}\left(1-\frac{K_{i, t}}{L_{i, t}}\right) & \text { if } E_{i, t}<0 \\ 0 & \text { if } E_{i, t}>=0 .\end{cases}
$$

\section{Simulation results}

A trend of increasing openness of inter-regional trade and financial flows has been empirically observed in the last decades world-wide, with many regions and countries becoming part of a single integrated system (Lane and Milesi-Ferretti, 2003). Part of the literature on globalization has focused on the consequences of such openness for the economic agents, both at micro- and at macro-level (Stiglitz, 2000; Summers, 2000).

In our model, in the presence of an increasing number of trading and financial linkages, agents in the economy become more interdependent. On the basis of the dynamics described in Sections 4 and 5, we study the impact of integration on (1) the frequency of individual defaults and (2) the frequency of large numbers of simultaneous failures. We study the dynamics of the economy for varying levels of openness, starting from a situation in which each region is separated from the others $(k=1)$, up to the case in which regions form a fully connected network $\left(k=n_{z}\right)$. Simulations were carried out with 50 regions. All details concerning the values of the parameters and the simulations procedures are reported in Appendix A.1.

The fraction $\nu_{f, t}$ of firms that are in bankrupted state is recorded at each time step. Since bankrupted firms are replaced by new firms, we are interested in the average fraction (over time) of failing firms (see also details in Appendix A.2). We refer to this in the following as the "average percentage of firms failing at any given time". Notice that this is not the cumulative number of bankruptcy observed during the simulation time. In contrast, it is meant to be a proxy of the probability of failure of the individual firm.

We first analyse separately the effect of the trade integration and the financial integration. The results are shown in Fig. 1. When the density of credit linkages is increased (left panel) - i.e. when firms borrow from banks located in an increasing number of other regions but sell only in one region - the percentage of defaulting firms increases (a part from small fluctuations). Conversely, when the density of trade linkages is increased (right panel) - i.e. when firms sell their goods in markets located in an increasing number of other regions, but borrow only from one region - the percentage of defaulting firms decreases steadily.

Notice that the reason why financial integration lead to more defaults is in the financial acceleration mechanism embedded in Eq. (21). If the interest rate is independent of the individual fragility and of the number of defaults in the bank's portfolio, then the number of defaults is independent of the network density (figure not shown). In other words, in the absence of acceleration, the net result of financial and trade integration would be univocally beneficial, in line with previous results (Battiston et al., 2012b).

Fig. 2 shows the case in which financial and trade integration increase together in the presence of financial acceleration. As firms have increasing access to the good and credit market of other regions, they largely benefit from price diversification and from accessing to lower interest rates. In the whole economy, the share of firms that goes bankrupt decreases from $4 \%$ to $1.7 \%$. Thus, an increase of connectivity leads to less individual failures until a minimum value. Such a minimum is considerably lower (more than 2 times) than the starting point, corresponding to isolated regions. Then, the failures slowly
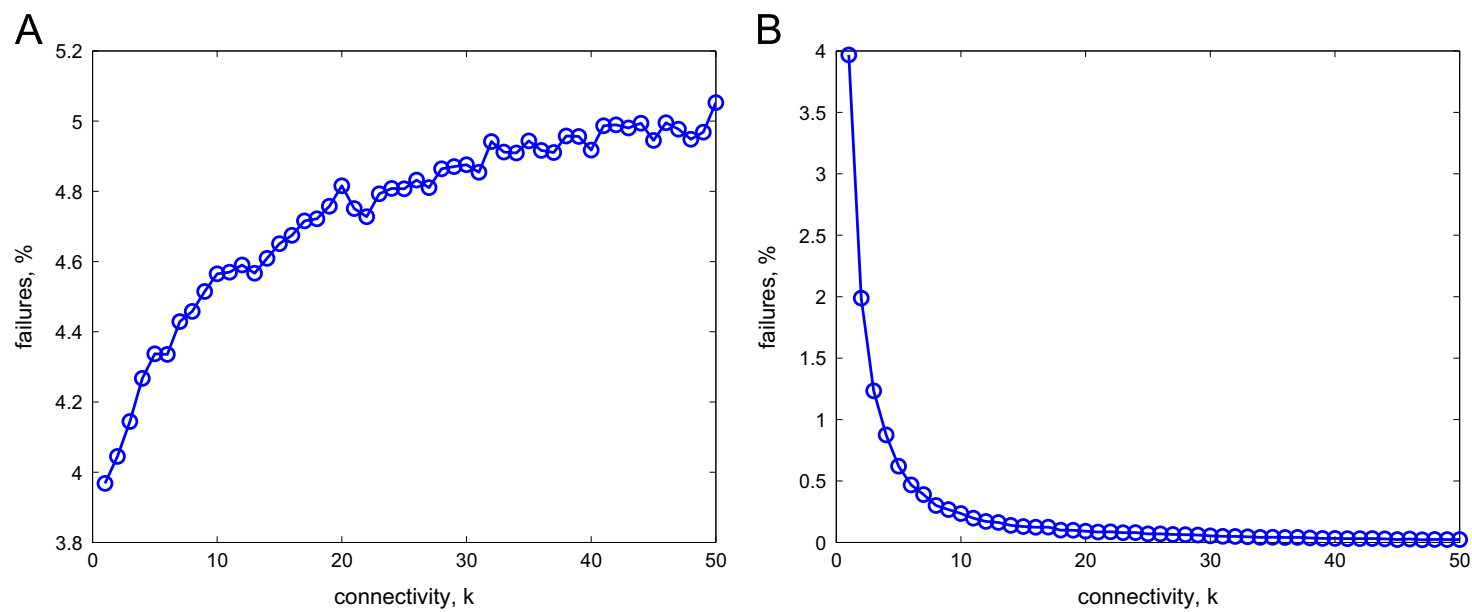

Fig. 1. Average percentage of firms' defaults at different levels $k$ of network density. (A) Only the density of credit linkages increases. (B) Only the density of trade linkages increases. 


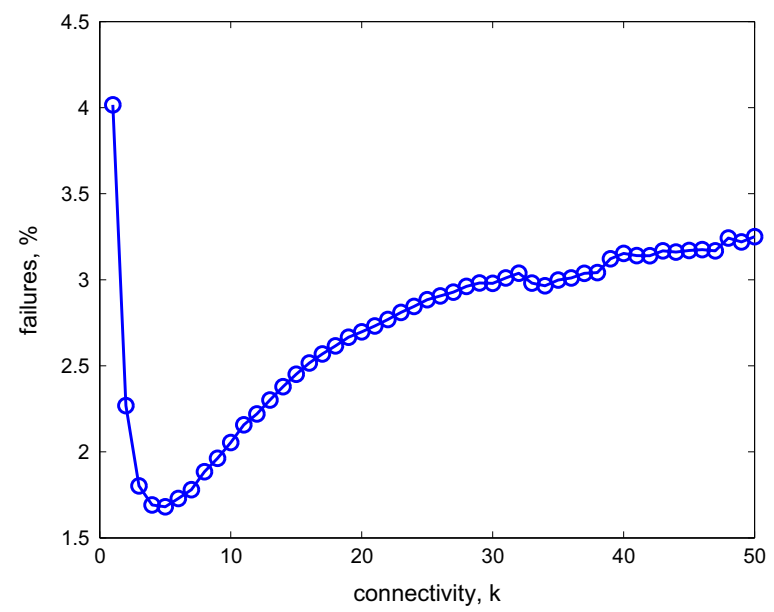

Fig. 2. Average percentage of firms' defaults at different levels $k$ of network density the case in which financial and trade integration increase together in the presence of financial acceleration.
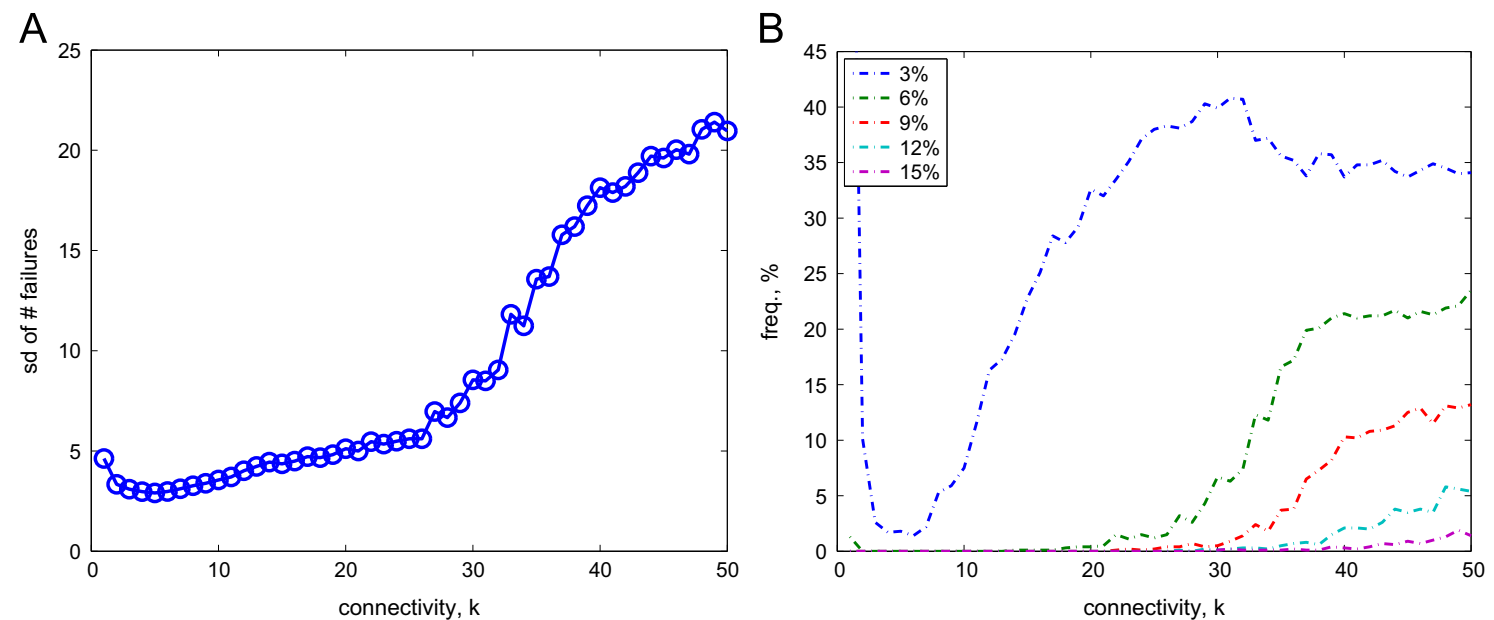

Fig. 3. (A) Standard deviation of the number of failures in each time step. Note that the standard deviation of the failures first reduces from 4.62 (with $k=1$ ) to 3.02 (with $k=5$ ), and then drastically increases to 20.97 with $k=50$. (B) Frequency of events in which the percentage of simultaneous failures is larger than a value $c$, for varying levels of connectivity $k$. The different curves correspond to $c=3 \%, 6 \%, 9 \%, 12 \%$ and $15 \%$. The result are obtained with $T=1000$ and averaged over 10 runs.

increase with higher $k$. This means that the two mechanisms of financial accelerator and contagion more than offset the benefits of risk diversification. Note that this result is robust to the values of several parameters (see Fig. B5 in Appendix B.3).

Although each firm individually takes advantage from diversification, as the economy becomes more connected, the system as a whole becomes less stable and faces a growing number of bankruptcies. Indeed, as shown in Fig. $3 \mathrm{~A}$, the standard deviation of the number of firm failed increases dramatically with the degree. This suggests the existence of cascades of defaults, which we then investigate in more detail.

Technically, the term cascade of defaults refers to a sequence of failures in which one or more failures at a given time step induce other failures at the next time step. This may also occur in our model through the mechanism of contagion, described after Eq. (23), that works as follows. The failure of few borrower firms induces the corresponding lender banks to increase the interest rate to the remaining firms. Among them, there can be fragile firms that are not able to bear the increase in the interest rate and fail at the next time step. Depending on the level of fragility across firms, this process may continue recursively and involve a large fraction of firms in the economy. The size of the cascade is simply the number of firms failing during this process. When regions are connected, failures in one region may induce failures in other regions, leading to global cascades.

Notice that, in practice, it is not convenient to deal with the size of the cascade, as defined above, in a dynamic model. This is because, over time: (i) two cascades originating at different locations may end up merging, and (ii) a new cascade can start at one location in the network before the previous one, occurring somewhere else, has ended. In addition, the nature of the cascade varies: a cascade can involve many firms but propagate slowly, few firms at a time; on the contrary it can be fast but involve many firms at once. In principle, simultaneous failures of firms can occur either due to common exogenous 

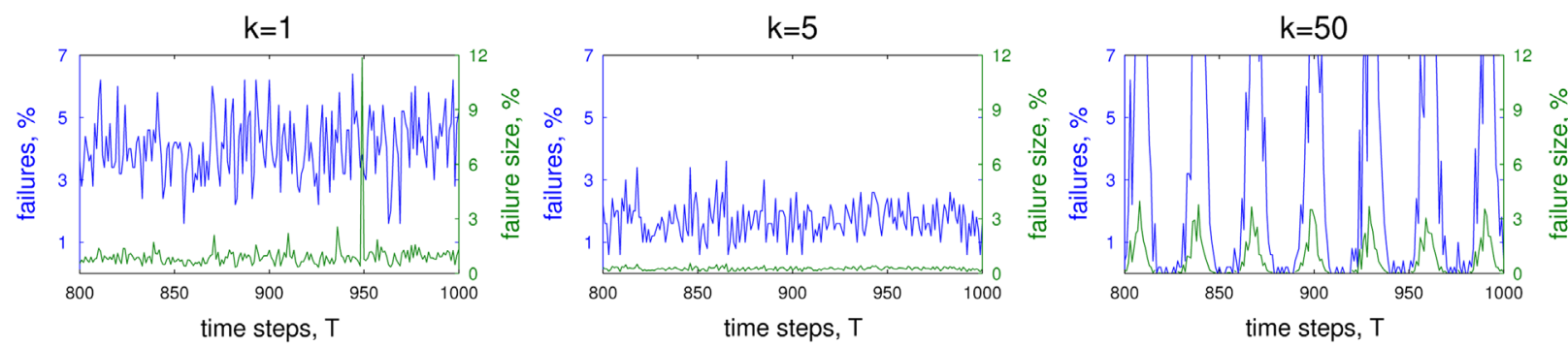

Fig. 4. Time evolution of the percentage of failures (scale on the left $y$-axis) and size (in equity) of the failed firms (scale on the right $y$-axis) in the time range $T=[800-1000]$. The degrees of firm connectivity considered are $k=1, k=5$ and $k=50$. (For interpretation of the references to color in this figure caption, the reader is referred to the web version of this paper.)

shocks (which are absent in our model), or by coincidence. However, a large number of simultaneous failures are very unlikely and it is typically due to an on-going cascade. For all the above reasons, and in particular for the difficulty of identifying precisely real cascades, as a measure of the level of distress in the system we take the fraction of firms that fail at the same time and we refer to it as "simultaneous failures". In particular, we are interested in the frequency, $\nu_{c}$, that the fraction of simultaneous failures at time $t, \nu_{f, t}$, is larger than a certain threshold. Over all the time steps $T$, we count those periods in which a fraction of failures larger than $c$ occurs. Then, we divide this value by the total number of periods $T$. In formal terms:

$$
\nu_{c}=\frac{\left|\left\{t: 1<=t<=T, \nu_{f, t}>c\right\}\right|}{T} .
$$

In the limit of a large number $T$ of periods, this frequency tends to the probability of numerous simultaneous failures.

As it is possible to observe in Fig. 3B, the frequency of events with a large number of simultaneous default increases with the density $k$. In particular, when the network is fully connected, although the average fraction of defaulting firms is about $3.2 \%$, the instantaneous fraction of defaults displays almost regular oscillations with peaks of about $15 \%$. Moreover, simultaneous defaults involving more than $9 \%$ of the firms are about 100 times larger with $k=50$ than with $k=5$.

The results can be read as follows. On the one hand, when the connectivity is not too high, firms benefit from the diversification on the trade across several regions but crises remain restricted to one region at a time and do not spread all over the economy. In this way, the average number of defaults remains low. On the other hand, when the connectivity is very high, the economy tends to synchronize.

In order to better understand the issue of simultaneous defaults, in Fig. 4, we show the time evolution of failures at different values of $k$. The percentage of failures first decreases as the degree $k$ increases, moving from an average of 4.02 with $k=1$ (left panel) to 1.67 when $k=5$ (middle panel). Then for higher values of degree, defaults increase (e.g., with degree $k=50$, the average percentage of failing firms is 3.25). Moreover, we see how failures tend to be synchronized over time (right panel). The reason is that, when the economy is fully integrated and the financial acceleration is present, sooner or later a shock that is perceived as unusual hits the firms and triggers a spiral in which banks raise the interest rate, more firms default and interest rate raises further. At the same time, after firms have defaulted new firms enter the market with better financial situation. As a result of these two processes, the number of defaults reaches a peak and then goes to zero.

Moreover, Fig. 4 reports the time evolution of the size, in terms of total equity of failed firms (curves in green). Failing firms have typically small size. Indeed, firms, when hit by a negative shock, enter a trend in which their financial position tend to worsen and their size to shrink, until they go bankrupt. In this respect, there is a body of literature which assumes that some financial organizations, but also non-financial ones, when they are considered by the government to be too important to the overall health of the economy (Gup, 2004) are simply "too-big-to-fail" (Chan-Lau, 2010). In our model, it can happen that medium and large size firms also fail. These rare events are observed in our model as well. For example, as it is possible to see in the first chart with $k=1$, the firms that go bankrupt in the economy, on average, represent the $2 \%$ of the whole firms' equity. However, around period 950 the failure of a large firm happens and the economy loses about $12 \%$ of its total equity value. In addition, one should consider that the size of simultaneous failures could have been even larger if we had modeled a less conservative behavior for the bank sector. Indeed, in this model the financial contagion is only due to the failure of firms and not of banks. Bank failures would have additional direct repercussions on firms: as they depend heavily on bank credit, the whole region where the bank fails would be depressed, and the consequences for the economy in terms of systemic risk would be even stronger.

Note that we obtain a similar finding with a network structure different from the one we have introduced in Section 5. See Appendix B.2 for the results obtained by simulating the model on the real Japanese network and other configurations.

Finally, it is worth noticing that as long as simultaneous failures involve only few firms, the economy can well absorb these negative shocks. On the contrary, when a large number of simultaneous failures become frequent (see Fig. 3), the economy experiences large oscillations and suffers from instability. As we show in Fig. 5, as long as $k$ is small, the aggregate equity displays moderate fluctuations. With large values, (e.g., $k=50$ ), instead, wide fluctuations appear, with consequent hampering of economic growth (see Fig. 5). In fact, when financial distress spreads in the whole economy, firms are always 

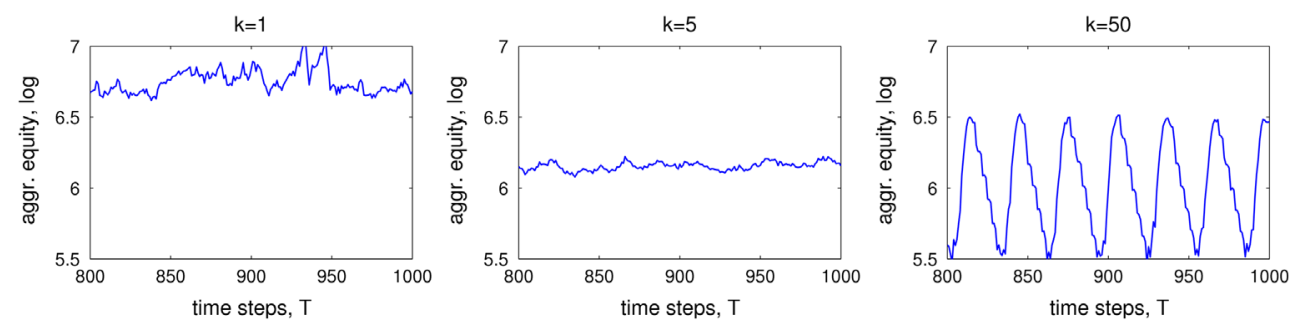

Fig. 5. Time evolution of the aggregate equity $(\log )$ in the time range $T=[800-1000]$, with firm connectivity $k=1, k=5$ and $k=50$.

charged an interest rate much higher than the risk-free rate, which prevents them to grow in size. In this way, they remain close to the bankruptcy level, and when some of them exit the market, the shock is transmitted to all the others, creating simultaneous failures.

\section{Conclusions}

In this paper we have studied the spread of financial distress in an economic system consisting of several regions. The focus of our investigation has been on how the level of openness across regional borders affects the fragility dynamics of firms and the probability of individual as well as systemic failures. In the spirit of previous works (Allen and Gale, 2000; Allen et al., 2012; Gai and Kapadia, 2010; Gai et al., 2011; Battiston et al., 2012b,a), we have compared the resilience of different static network architectures. In particular, we have focused on different levels of the average number of connections.

From a policy perspective, our work contributes to the growing literature on the relation between interconnectedness and systemic risk. Our finding is that in the absence of financial acceleration network density both on trade and credit is always beneficial. In contrast, in the presence of financial acceleration (i.e. the interest rate charged by a bank to a firm is a function of the history of the fragility of the firms in the bank's portfolio), the benefit of risk diversification on the trade network is offset at some point by the risk of contagion on the credit network.

One limitation of our model is that, because of a number of simplifications, the model cannot be easily calibrated at this stage and thus it is not able to provide reliable numbers on the optimal connectivity levels. In particular, further work should try to relate our model to the process of transformation of the banking sector in various countries in the last decades. For instance, Illueca et al. (2014) have studied how joint bank exposures have increased in Spain after the liberalization of the financial sector and the increase of the regional outreach of formerly local savings banks.

The intuition behind our results is that when firms concentrate both trade and credit within their own region, they are only exposed to local shocks. Instead, when firms trade and borrow across borders, regions in the system become interdependent and crises are not local any longer. As long as the average degree of connectivity is low, firms take advantage of price diversification while contagion remains local. On the other hand, with full connectivity, the diversification benefits are overcome by the financial accelerator and the contagion mechanisms, and the financial distress diffuses in the whole system.

The central assumption behind the tradeoff results is that financial acceleration and contagion are at work through the dynamics of the interest rate. There are theoretical arguments why financial acceleration could be quite pervasive in real economic settings (Bernanke et al., 2000; Stiglitz and Greenwald, 2003). To what extent and in which situations financial acceleration is at work remains an open question. Also, it remains to be clarified empirically what is the exact dynamics. Our claim is that in the presence of positive feedbacks in the relation between the financial fragility of firms and the interest rate charged, such as the one emerging from the financial acceleration mechanism proposed here, the connectivity on credit can become at some point detrimental.

To this end, we have adopted from Delli Gatti et al. $(2005,2010)$ the mechanism by which a large fraction of 'risky' firms in the bank's portfolio imply a high rate demanded by the bank from the next potential borrower. Similar to Gai et al. (2011), we focus on a given exogenous level of connections and exposures and we do not develop an optimization approach on the side of the bank. Future work could extend this aspect of the model.

The model can be used for a number of further investigations. First, one could consider several network structures and compare their resilience to systemic risk. In this respect, it would be worth considering structures reflecting the empirical distributions of the number of banks and regions per firm. The network structure could also be endogenized and let evolve in time according to some link formation rule. In particular, one important limitation of the present model is that we do not develop an optimization approach for the credit demand of firms. Empirically, firms are observed to maintain several credit lines. How to explain this empirical fact in terms of an optimal credit demand rule remains an open question.

Second, one could add heterogeneity among firms and banks on the basis of their geographical preferences. For example, by assuming that smaller firms prefer local bank contacts, while larger ones are more global and establish relations with foreign banks. Moreover, one could assume the existence of "costs of going abroad". Although nowadays decreasing (thanks 
to the advances in information and communication technology and to the international process of making laws and procedures homogeneous) these costs can still influence the firm decision to interact with agents located in many other regions.

Finally, one could introduce other forms of financing for firms and investigate the possible implications on the propagation of financial distress. For example, the possibility for firms to issue and purchase corporate bonds creates direct financial ties among firms, which may foster the propagation of financial fragility. Finally, a validation of the model with empirical data would shed light on the correct calibration of the model.

\section{Acknowledgments}

The first version of this work was written while S.B. and S.V. were employed at the Chair of Systems Design at ETH Zurich, lead by Frank Schweitzer, to whom they are thankful for support and guidance. The authors acknowledge financial support from the ETH Competence Center "Coping with Crises in Complex Socio-Economic Systems" [CHIRP 1 grant no. CH1-01-08-2], the European FET Open Project "FOC" [grant no. 255987]. S.B. acknowledge the Swiss National Fund Professorship grant no. PP00P1-144689.

\section{Appendix A. Simulation procedure}

In this Appendix, we provide information on the setting used for the computer simulations and how we have performed such simulations.

\section{A.1. Parameter setting}

All simulations refer to a benchmark parameter setup. We considered the economy as divided in $n_{z}=50$ regions, each of them populated by $n_{f}=10$ firms and $n_{b}=1$ bank. Hence, there are $n_{f} \cdot n_{z}=500$ firms and $n_{b} \cdot n_{z}=50$ banks in the whole economy. In total, there are 9 parameters, which are calibrated as follows: $\alpha=0.08, \gamma=0.1, \eta=0.8, \psi=0.75, \bar{r}=0.02$, $\theta=1.7, r_{\max }^{f}=0.04, r_{\max }^{b}=0.04$ and $a=0.005$.

The values of these parameters have been assigned in an empirically plausible range. In some cases, we have proposed the values assigned in the reference model (Delli Gatti et al., 2005). In particular, $\psi$, the parameter for the variable costs, has been defined so that, on average, firms are left with the $25 \%$ of revenue to pay the financial costs and, eventually, storing positive profits. The parameter $\eta$ for the constraint in the capital reduction has been fixed to 0.8 so that from a period to the following one a firm cannot liquidate more than $20 \%$ of its capital level. Both values are empirically plausible. Moreover, we have run robustness checks around these two values. The bank risk coefficient, $\alpha$, has been fixed in order to reflect the Basel agreements. The risk-free rate, $\bar{r}$, has been set as close to the one currently in use in Europe, while $r_{\max }^{f}$ and $r_{\max }^{b}$ are chosen so that the maximum level of the interest rate charged by banks to their portfolio firms cannot exceed $10 \%$. The parameter $a$ is defined so that the increase of interest rare is gradual, i.e. $\pm 0.5 \%$. Finally, $\theta$, which corresponds to number of standard deviations above which a shock triggers the reaction of the bank, is set to 1.7 . In this way, the chance of occurrence of such a shock is only $4 \%$.

\section{A.2. Simulation procedure}

The simulation starts at time $t=1$ and ends at $t=1000$, when the system has reached sufficiently stable patterns. At $t=1$ all banks are identical, and all firms are identical, and are assigned certain initial values. Homogeneity of initial conditions is assumed in order to not bias the dynamics of the system, and to better appreciate the emergent heterogeneity of the firms' and banks' dynamics. For firms, the initial level of equity base, liability, capital and profits are $E_{i, 0}=2, L_{i, 0}=8, K_{i, 0}=10$, $P_{i, 0}=0$ and $K^{\mathrm{min}}=2$. The aggregate credit supply of each bank is given by $L_{j, 0}=L_{i, 0} n_{f}=80$, while the bank's equity base can be derived by the definition of credit supply (see Eq. (19)): $E_{j, 0}=\alpha L_{j, 0}=64$. After bankruptcy at time $t$, firms and banks failed are reintroduced at $t+1$ with an endowment equal to their initial level of net worth, liabilities and capital. Once we have set all the parameters and the initial conditions, we run the algorithm for each degree of connectivity: $k=1, \ldots, n_{z}$. That is, in each simulation we suppose that all the companies have the same degree $k$. In this way, we have the time evolution of the key variables, like the number of individual failures, the level of production, etc., at different levels of market integration. In Fig. A1, a diagram with the description of the algorithm is presented. Moreover, in order to also better clarify the procedure employed in the simulation, a bullet point with the description of the work flow is illustrated in what follows:

1. set parameters \& initial conditions, and simulate the model for $t=1 \ldots 1000$; this is referred to as "a run";

2. for each time step, we record the fraction of firms that fail, as well as aggregate values of economic variables described in the model, e.g. output, profit, etc.

3. perform several runs;

4. compute average, across time and runs, of fraction of failing firms;

5. vary the level of connectivity and/or other parameters.

Variations in the values of the parameters of the model differ in term of the impact that they have on the overall dynamics. Some parameters, e.g., $g$, do not affect the outcome remarkably. Other parameters e.g., $\alpha$ or the parameters 


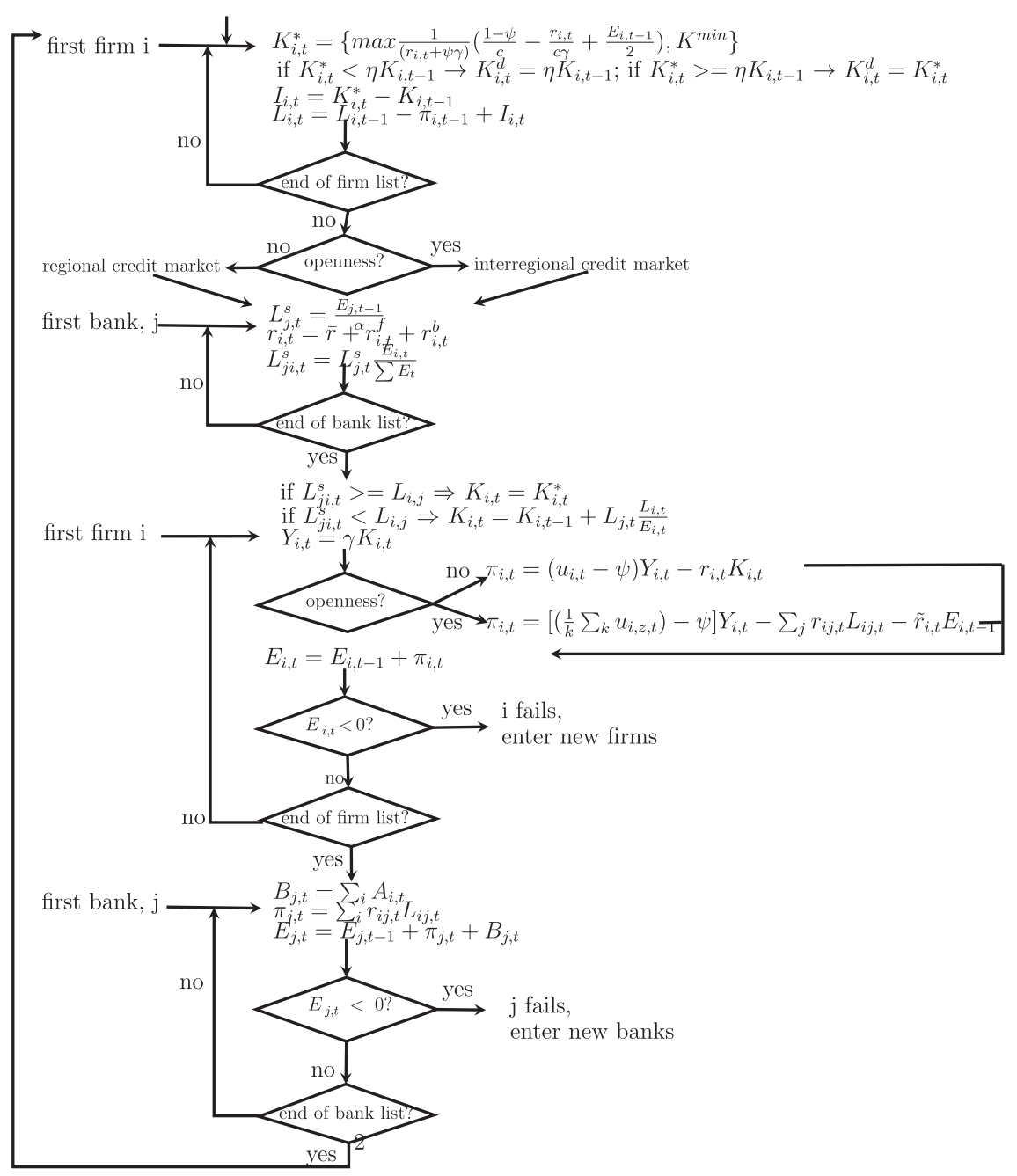

Fig. A1. Diagram of the main loop algorithm.

referring to the interest rate, are bound to be in a narrow empirical range. Moreover, in some cases, the outcome of the robustness check is quite obvious. For example, an increase of the parameters defining the interest rate will rise the firm financing costs, causing higher probability of bankruptcy, larger simultaneous failures and a reduction in the production level. Therefore, we focus on the two parameters $\eta$ and $\psi$, for which ex ante variations do not have a clear impact.

\section{Appendix B. Robustness analysis}

In this Appendix, we provide information on the results of the robustness analysis.

\section{B.1. Robustness analysis of the interest rate definition}

In order to better understand the behavior of the interest rate $r$ and its relation to the firm fragility $\phi_{i, t}$ (see Eq. (21)), here we report in Fig. B1 the scatter plot of the interest rate charged to each firm $i$ against its level of fragility, for 500 time steps $(T=500-1000)$ at different connectivity levels $k$. Each dot corresponds to a given firm at a given time. Different colors correspond to different times. The patterns observed in the bottom right plot reflect a certain synchronization in the level of fragility across firms when the connectivity is very high.

In addition, Fig B2 is obtained from Fig. B1 by binning the fragility range and by taking, for each bin, the average $( \pm s t d)$ of the values of interest rate corresponding to fragility values in that bin. As we can observe, on average the interest rate increases monotonically with the fragility and saturates at a maximum value. Moreover, the higher the level of connectivity in the network, the higher is the curve. 

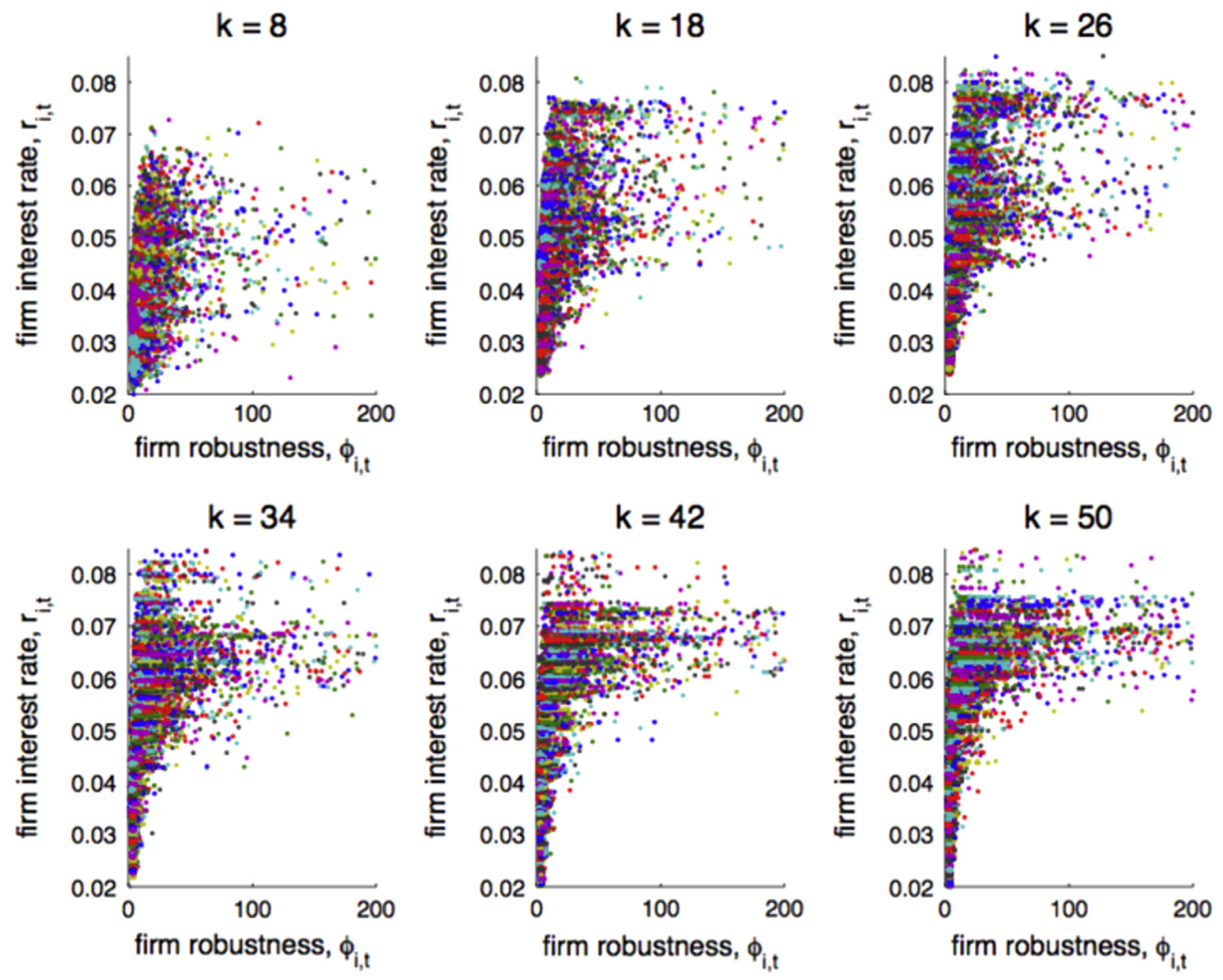

Fig. B1. Scatter plot of the interest rate charged to each firm $i$ against its level of fragility, for 500 time steps $(T=500-1000)$ at different connectivity levels $k=[8,18,26,34,42,50]$. (For interpretation of the references to color in this figure caption, the reader is referred to the web version of this paper.)

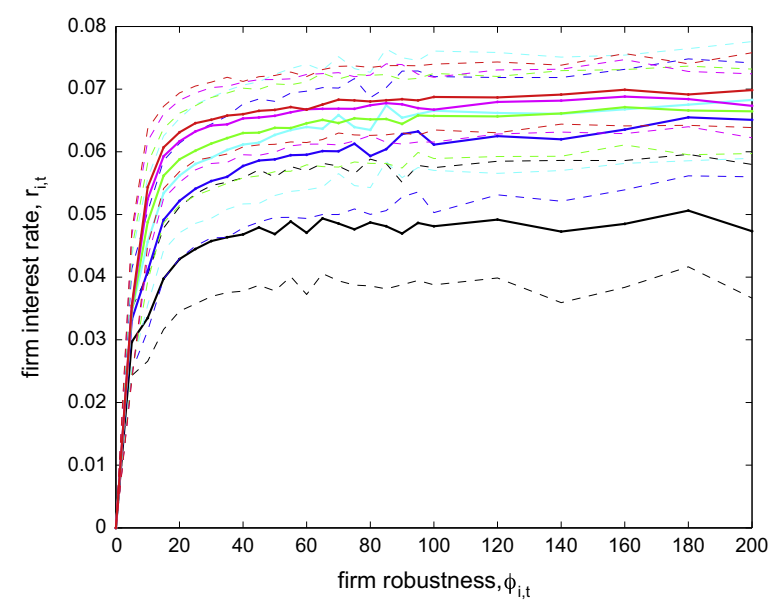

Fig. B2. Average interest rate ( \pm standard deviation in dashed lines) at binned fragility values. Each curve corresponds to a different degrees $k$ of diversification: $k=8$ is black, $k=18$ is in blue, $k=26$ in cyan, $k=34$ in green, $k=42$ in magenta, $k=50$ in red. (For interpretation of the references to color in this figure caption, the reader is referred to the web version of this paper.) 

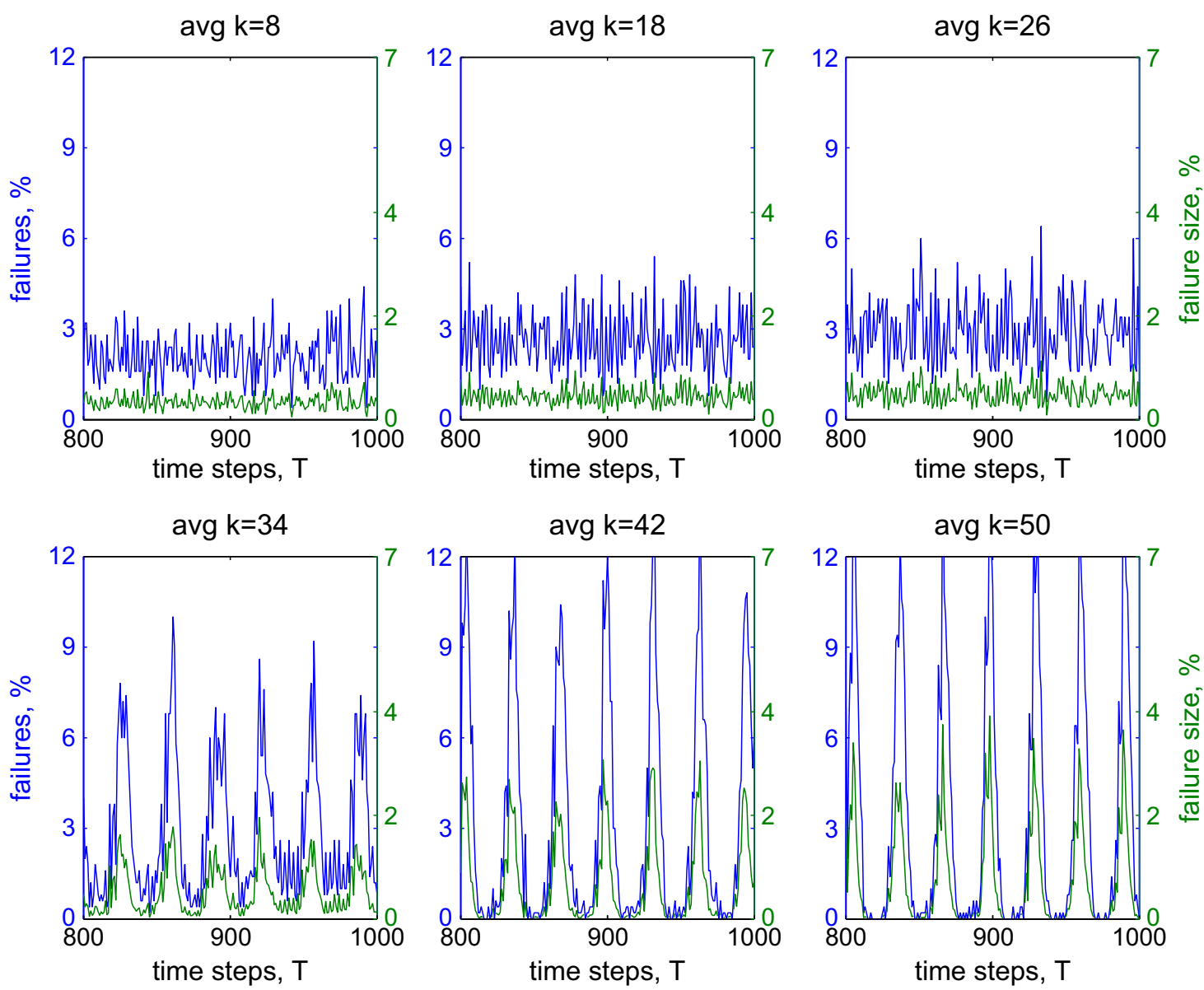

Fig. B3. Time evolution of the percentage of failures (scale on the left $y$-axis) and size (in equity) of the failed firms (scale on the right $y$-axis) in the time range $T=[800-1000]$. The degrees of firm's connectivity considered are $k=[8,18,26,34,42,50]$, cfr. Fig. 4 .

\section{B.2. Robustness analysis of the network structure}

In this section we perform a robustness analysis of the results by considering different network structures.

First, we perform simulations where actors of one region have access to actors belonging to other regions not following a clockwise connection rule, but connecting to actors on both sides along the ring. Both the average fraction of firms in default and its standard deviation depend on the degree of diversification. This indicates that, at least if the degree is homogeneous, the results are robust to changes in the way regions are connected on the ring. The result suggests that in our model, the number of connections among regions matters more than the way these connections are arranged, if the structure is homogeneous in the degree. The two mechanisms at work are the risk diversification and the contagion. For the risk diversification, only the number of regions matters in our model to determine the fluctuations on the prices. For the contagion, if regions have similar degree, the main driver is the number of firms defaulting in each region, which in turn depends mostly on the degree.

Further, we have used real data credit relationships between Japanese firms and financial institutions in the year 2005. The dataset is the same that was studied in De Masi et al. (2011) where the firms are those quoted in the Japanese stockexchange market, while information on the borrowing relationships are compiled from firms' financial statements, integrated by surveys of Nikkei Media Marketing Inc. in Tokyo. Financial institutions consist of long-term credit banks and insurance companies, representative of the universe of financial institutions in Japan.

The size of this dataset (i.e., 2674 firms, 182 banks and 21,811 credit relations) confronted us with computational difficulties in the simulations. We have thus extracted a random sub-network trying to obtain approximately the same number of banks, firms and links that we used in the first part of the analysis and trying also to maintain the original statistical properties, such as the average degree and the degree distribution of both the number of firms per bank and the number of banks per firm. Notice that both in the original dataset and in the sub-network the average number of banks per firm is about 8 (De Masi and Gallegati, 2007; De Masi et al., 2011).

As we can observe in Figs. B3 and B4, the results obtained on the Japanese network are similar to those reported in Section 6 with a regular graph. The case $k=8$ looks similar to the case $k=5$ in Section 6 , Fig. 4 . When we add links randomly 


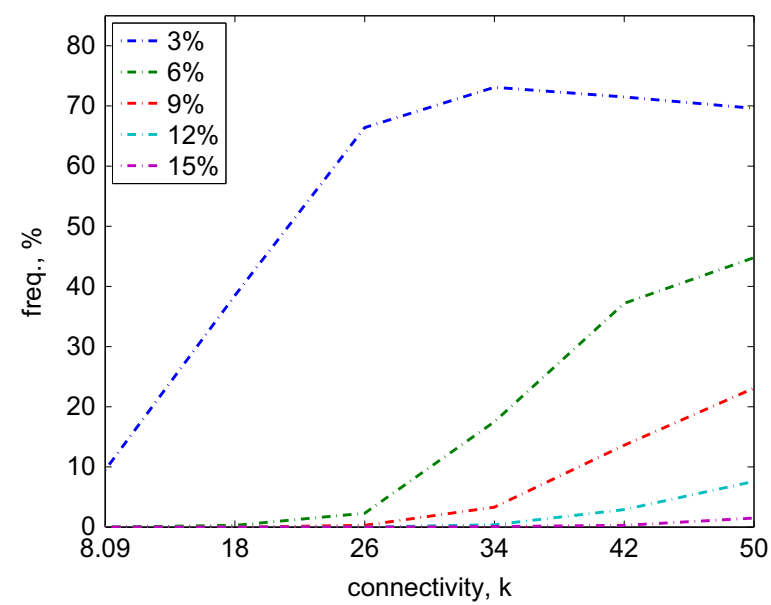

Fig. B4. Frequency of events in which the percentage of simultaneous failures is larger than a value $c$, for varying levels of connectivity $k$. The different curves correspond to $c=3 \%, 6 \%, 9 \%, 12 \%$ and $15 \%$. The result are obtained with $T=1000$ and averaged over 10 runs, cfr. Fig. 3.
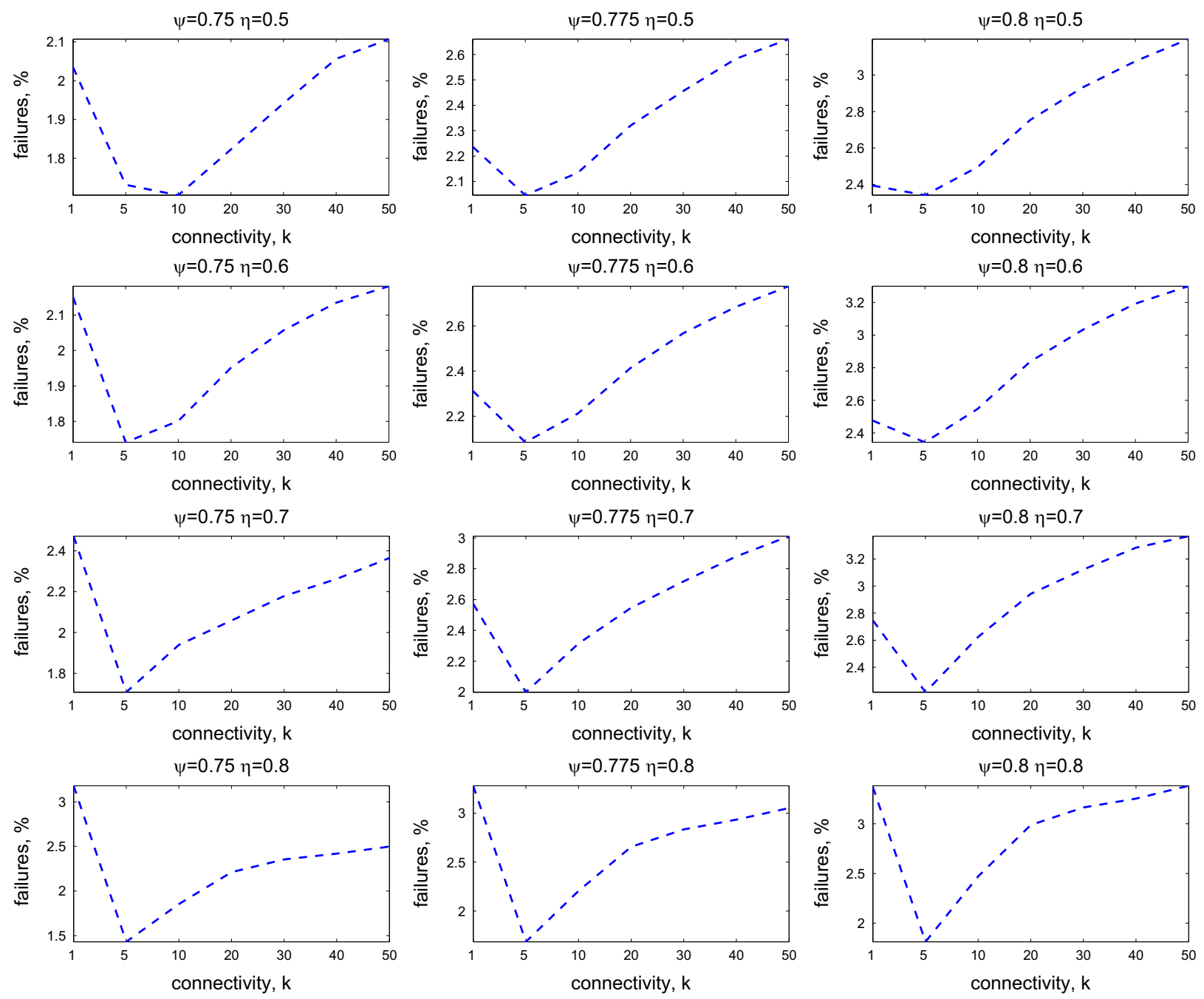

Fig. B5. Average percentage of failures at different connectivity $k$, varying the parameters $\eta$ and $\psi$. 

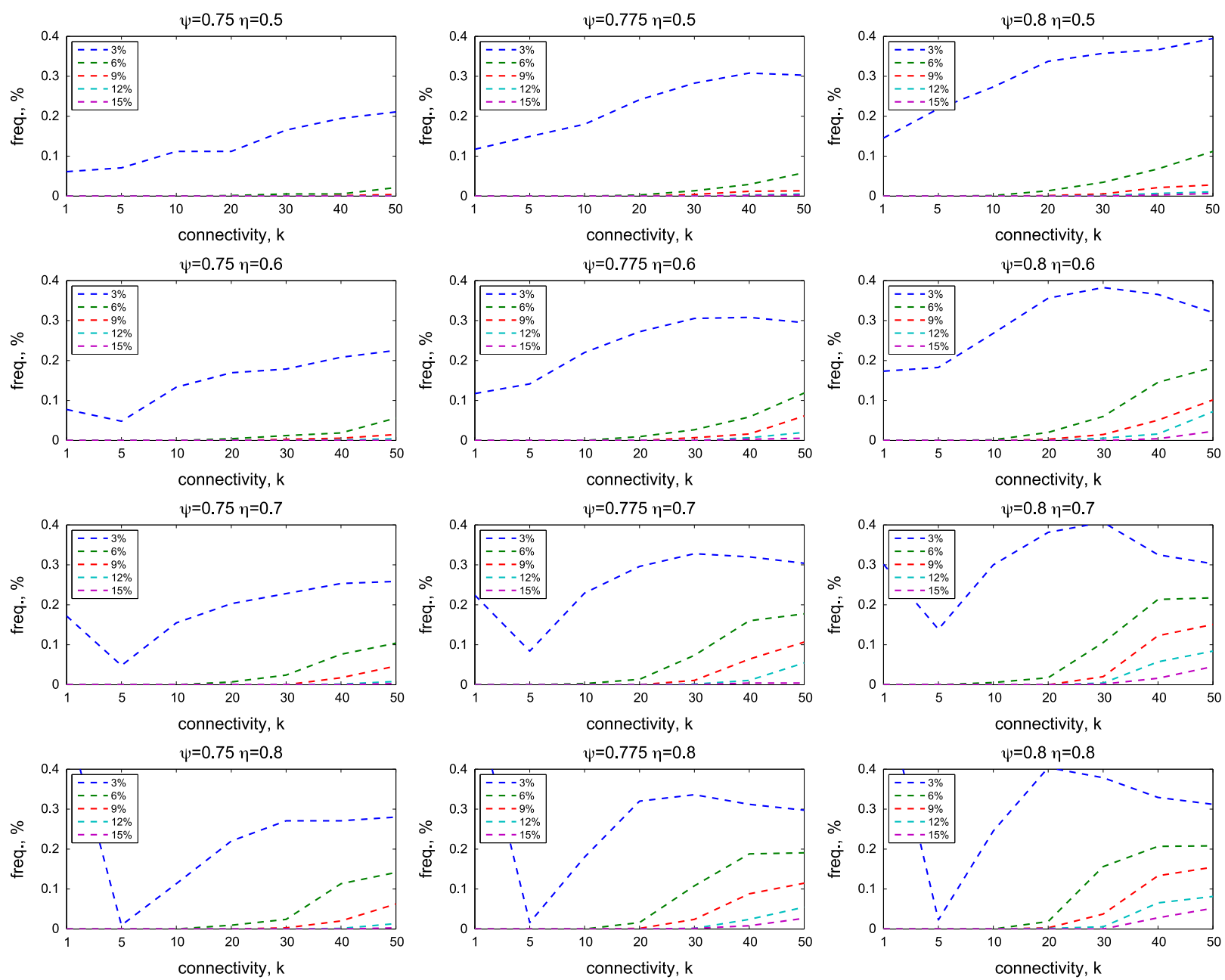

Fig. B6. Frequency of events in which the percentage of simultaneous failures is larger than a value $c$, for varying levels of connectivity $k$ and varying parameters of $\eta$ and $\psi$.

(thus increasing $k$ ), the number of failures increases. Moreover, large numbers of simultaneous failures emerge (compare Fig. 3, right side, with Fig. B3).

This finding has two implications. First, it suggests that the way we constructed the network structure in the first part of the analysis does not affect the results. Second, the level of connectivity in the empirical network structure is close to the most desirable one from the point of view of systemic risk. We cannot say how general this result is and in any case it refers only to one particular year. A systematic analysis on other empirical structures is beyond the scope of this paper.

\section{B.3. Robustness analysis of parameters}

In this section we carry out a robustness analysis of the effect of the two parameters $\eta$ (referring to the restriction on the capital reduction) and $\psi$ (referring to the variable costs). As one can see in Fig. B5, the number of failures as a function of $k$ remains non-monotonic if we vary $\eta$ and $\psi$. In Fig. B6, we report the frequency of numbers of simultaneous failures at different values of $\eta$ and $\psi$. Also in this case, the general trend does not change: a large number of simultaneous failures become more frequent as $k$ increases.

However, the model is quite sensitive to the parameter $\psi$, which defines the level of the variable costs. This is due to the multiplicative nature of profit accumulation in the model. If costs are too low no firm will ever default. If costs are too high the economy never grows. The interesting range in which there are some failures is around 0.75 . Here, we vary $\psi$ in the range from $75 \%$ to $80 \%$, corresponding to a variation of $5 \%$ in revenues, quite significant for a firm. Indeed, variable costs can affect considerably both firm capacity to pay all the liabilities and firm level of optimal capital. 


\section{References}

Agarwal, R., Ann Elston, J., 2001. Bank-firm relationships, financing and firm performance in Germany. Econ. Lett. 72 (2), $225-232$.

Allen, F., Babus, A., Carletti, E., 2012. Asset commonality, debt maturity and systemic risk. J. Financ. Econ. 104 (3), $519-534$.

Allen, F., Gale, D., 2000. Financial contagion. J. Polit. Econ. 108 (1), 1-33.

Amini, H., Cont, R., Minca, A., 2012. Stress testing the resilience of financial networks. Int. J. Theor. Appl. Finance 15 (01).

Battiston, S., Delli Gatti, D., Gallegati, M., Greenwald, B., Stiglitz, J., 2007. Credit chains and bankruptcy propagation in production networks. J. Econ. Dyn. Control 31 (6), 2061-2084.

Battiston, S., Delli Gatti, D., Gallegati, M., Greenwald, B.C.N., Stiglitz, J.E., 2012a. Credit default cascades: when does risk diversification increase stability?. J. Financ. Stab. 8 (3), 138-149. URL 〈http://www.sciencedirect.com/science/article/pii/S1572308912000125〉.

Battiston, S., Gatti, D.D., Gallegati, M., Greenwald, B.C.N., Stiglitz, J.E., 2012b. Liaisons dangereuses: increasing connectivity, risk sharing, and systemic risk. J. Econ. Dyn. Control 36 (January (8)), 1121-1141. URL 〈http://www.sciencedirect.com/science/article/pii/S0165188912000899〉.

Bernanke, B., Gertler, M., 1989. Agency costs, net worth, and business fluctuations. Am. Econ. Rev., 14-31.

Bernanke, B., Gertler, M., 1995. Inside the black box: the credit channel of monetary policy transmission. J. Econ. Perspect., 27-48.

Bernanke, B., Gertler, M., Gilchrist, S., 2000. The financial accelerator in a quantitative business cycle framework. In: Taylor, J., Woodford, M. (Eds.), Handbook of Macroeconomics, North-Holland, Amsterdam, The Netherlands.

Boissay, F., 2006. Credit Chains and the Propagation of Financial Distress. Available at SSRN 872543 (573).

Cajueiro, D., Tabak, B., 2008. The role of banks in the brazilian interbank market: does bank type matter?. Physica A: Stat. Mech. Appl. 387 (27), 6825-6836.

Carayol, N., Roux, P., Yildizoglu, M., 2008. Inefficiencies in a model of spatial networks formation with positive externalities. J. Econ. Behav. Organ. 67 (2), 495-511.

Chan-Lau, A.J., 2010. Financial Crisis, Interconnectedness and Regulatory Capital. NBER Working Papers 1552043, National Bureau of Economic Research.

Dasgupta, A., 2004. Financial contagion through capital connections: a model of the origin and spread of bank panics. J. Eur. Econ. Assoc. 2 (6), 1049-1084.

De Masi, G., Fujiwara, Y., Gallegati, M., Greenwald, B., Stiglitz, J., 2011. An analysis of the japanese credit network. Evolut. Inst. Econ. Rev. 7 (2), $209-232$.

De Masi, G., Gallegati, M., 2007. Debt-credit economic networks of banks and firms: the Italian case. In: Econophysics of Markets and Business Networks: Proceedings of the Econophys-Kolkata III. Springer, Milan, Italy, p. 159.

Degryse, H., Ongena, S., 2005. Distance, lending relationships, and competition. J. Finance, 231-266.

Degryse, H., Van Cayseele, P., 2000. Relationship lending within a bank-based system: evidence from European small business data. J. Financ. Intermediation 9 (1), 90-109.

Delli Gatti, D., Di Guilmi, C., Gallegati, M., Giulioni, G., 2007. Financial fragility, industrial dynamics, and business fluctuations in an agent-based model. Macroecon. Dyn. 11 (S1), 62-79.

Delli Gatti, D., Gallegati, M., Greenwald, B., Russo, A., Stiglitz, J., 2009. Business fluctuations and bankruptcy avalanches in an evolving network economy. J. Econ. Interact. Coord. 4 (2), 195-212.

Delli Gatti, D., Gallegati, M., Greenwald, B., Russo, A., Stiglitz, J., 2010. The financial accelerator in an evolving credit network. J. Econ. Dyn. Control 34 (9), $1627-1650$.

Delli Gatti, D., Guilmi, C., Gaffeo, E., Giulioni, G., Gallegati, M., Palestrini, A., 2005. A new approach to business fluctuations: heterogeneous interacting agents, scaling laws and financial fragility. J. Econ. Behav. Organ. 56 (4), 489-512.

Detragiache, E., Garella, P., Guiso, L., 2000. Multiple versus single banking relationships: theory and evidence. J. Finance 55 (3), $1133-1161$.

Dornbusch, R., Park, Y., Claessens, S., 2000. Contagion: how it spreads and how it can be stopped?. World Bank Res. Obs. 15 (2).

Farinha, L., Santos, J., 2002. Switching from single to multiple bank lending relationships: determinants and implications. J. Financ. Intermediation 11 (2), 124-151.

Gai, P., Haldane, A., Kapadia, S., 2011. Complexity, concentration and contagion. J. Monet. Econ. 58 (5), $453-470$.

Gai, P., Kapadia, S., 2010. Contagion in financial networks. Proc. R. Soc. A: Math. Phys. Eng. Sci. 466 (March (2120)), 2401-2423. URL 〈http://rspa.royalso cietypublishing.org/cgi/content/abstract/466/2120/2401>.

Goldstein, I., Pauzner, A., 2004. Contagion of self-fulfilling financial crises due to diversification of investment portfolios. J. Econ. Theory 119 (1), 151-183.

Greenwald, B., Stiglitz, J., 1990. Macroeconomic models with equity and credit rationing. In: Asymmetric Information, Corporate Finance, and Investment, p. 15 (chapter 1)

Greenwald, B., Stiglitz, J., 1993. Financial market imperfections and business cycles. Q. J. Econ., 77-114.

Gup, B., 2004. Too Big to Fail: Policies and Practices in Government Bailouts. Praeger Publishers, Santa Barbara, California, USA.

Haldane, A., 2009. Rethinking the financial network. Speech delivered at the Financial Student Association, Amsterdam, April.

Horst, U., 2007. Stochastic cascades, credit contagion, and large portfolio losses. J. Econ. Behav, Organ. 63 (1), 25-54.

Illueca, M., Norden, L., Udell, G.F., 2014. Liberalization and risk-taking: evidence from government-controlled banks. Rev. Finance 18 (4), $1217-1257$.

IMF, April 2006. Globalization and Inflation. International Monetary Fund, Washington, D.C., USA.

Iori, G., Jafarey, S., Padilla, F., 2006. Systemic risk on the interbank market. J. Econ. Behav. Organ. 61 (4), $525-542$.

Jackson, M., Watts, A., 2002. The evolution of social and economic networks. J. Econ. Theory 106 (2), $265-295$.

Kali, R., Reyes, J., 2009. Financial contagion on the international trade network. Econ. Inq.

König, M., Battiston, S., Napoletano, M., Schweitzer, F., 2011. Recombinant knowledge and the evolution of innovation networks. J. Econ. Behav. Organ. 79 (3), 145-164.

König, M., Battiston, S., Napoletano, M. Schweitzer, F., 2012. The efficiency and stability of r\&d networks. Games Econ. Behav. 75 (2), $694-713$.

Lane, P., Milesi-Ferretti, G., 2003. International Financial integration. IMF Staff Papers, pp. 82-113.

Lorenz, J., Battiston, S., 2008. Systemic risk in a network fragility model analyzed with probability density evolution of persistent random walks. Networks and Heterogeneous Media, pp. 185-200.

Lublóy, Á, Szenes, M., 2008. The network of corporate clients: customer attrition at commercial banks. J. Stat. Mech.: Theory Exp. 2008 , P12014.

Martínez-Jaramillo, S., Pérez Pérez, O., Avila Embriz, F., López Gallo Dey, F., 2010. Systemic risk, financial contagion and financial fragility. J. Econ. Dyn. Control.

Nier, E., Yang, J., Yorulmazer, T., Alentorn, A., 2007. Network models and financial stability. J. Econ. Dyn. Control 31 (6), $2033-2060$.

Ogawa, K., Sterken, E., Tokutsu, I., 2007. Why do Japanese firms prefer multiple bank relationship? Some evidence from firm-level data. Econ. Syst. 31 (1), 49-70.

Ongena, S., Smith, D., 2000. What determines the number of bank relationships? Cross-country evidence. J. Financ. Intermediation 9 (1), 26-56.

Prasad, E., Rogoff, K., Wei, S., Kose, M., 2003. Effects of financial globalisation on developing countries: some empirical evidence. Econ. Polit. Wkly. 38 (41), 4319-4330.

Sharpe, S., 1990. Asymmetric information, bank lending and implicit contracts: a stylized model of customer relationships. J. Finance, $1069-1087$.

Stark, D., Vedres, B., 2006. Social times of network spaces: network sequences and foreign investment in Hungary. Am. J. Sociol. 111 (5), 1367-1411.

Stiglitz, J., 2000. Capital market liberalization, economic growth, and instability. World Dev. 28 (6), $1075-1086$.

Stiglitz, J., 2010. Risk and global economic architecture: why full financial integration may be undesirable. Am. Econ. Rev. 100 (2), 388-392.

Stiglitz, J., Greenwald, B., 2003. Towards a New Paradigm in Monetary Economics. Cambridge University Press, Cambridge, UK.

Summers, L., 2000. International financial crises: causes, prevention, and cures. Am. Econ. Rev., 1-16.

Vitali, S., Battiston, S., 2011a. Geography versus topology in the European ownership network. New J. Phys. 13 (6), 063021.

Vitali, S., Glattfelder, J., Battiston, S., 2011. The network of global corporate control. PloS One 6 (10), e25995.

von Thadden, E., 2004. Asymmetric information, bank lending and implicit contracts: the winner's curse. Finance Res. Lett. 1 (1), 11-23.

Wagner, W., 2011. Systemic liquidation risk and the diversity-diversification tradeoff. J. Finance 66 (4 (August)), $1141-1175$. 